\title{
A NMR-based metabolomics approach for the assessment of inhaled pharmacotherapy in patients with Chronic Obstructive Pulmonary Disease
}

\author{
Alessia Vignoli ${ }^{1,2}$, Giuseppe Santini ${ }^{3,4}$, Leonardo Tenori ${ }^{1,5}$, Giuseppe Macis ${ }^{6}$, Nadia Mores ${ }^{3,4}$, \\ Francesco Pagano $^{7,8}$, Tim Higenbottam ${ }^{9}$, Claudio Luchinat ${ }^{1,2,10, *}$, Paolo Montuschi ${ }^{3,4, *}$
}

${ }^{1}$ Magnetic Resonance Center (CERM), University of Florence, Sesto Fiorentino, Italy

${ }^{2}$ Consorzio Interuniversitario Risonanze Magnetiche di Metallo Proteine (CIRMMP), Florence, Italy ${ }^{3}$ Department of Pharmacology, Faculty of Medicine, Catholic University of the Sacred Heart, Rome, Italy

${ }^{4}$ Pharmacology Unit, University Hospital Agostino Gemelli Foundation, IRCCS, Rome, Italy ${ }^{5}$ Department of Experimental and Clinical Medicine, University of Florence, Florence, Italy ${ }^{6}$ Imaging Diagnostics, University Hospital Agostino Gemelli Foundation, IRCCS, Rome, Italy ${ }^{7}$ Ageing Unit, University Hospital Agostino Gemelli Foundation, IRCCS, Rome, Italy

${ }^{8}$ Department of Internal Medicine and Geriatrics, Faculty of Medicine, Catholic University of the Sacred Heart, Rome, Italy

${ }^{9}$ Faculty of Pharmaceutical Medicine, Royal College of Physicians, London, United Kingdom

${ }^{10}$ Department of Chemistry “Ugo Schiff”, University of Florence, Sesto Fiorentino, Italy

- Supplementary Table S1. Classification parameters for statistically significant comparisons among different pharmacological treatments from visit 1 to visit 4 based on mPLS models built on urine, serum, EBC and sputum supernatant (SS) NMR spectroscopic data in 14 patients with COPD.

- Supplementary Table S2. Paired comparison of serum metabolite concentrations at each visit using Wilcoxon signed-rank test.

- Supplementary Table S3. Paired comparison of urine metabolite concentrations at each visit using Wilcoxon signed-rank test.

- Supplementary Table S4. Paired comparison of exhaled breath condensate (EBC) metabolite concentrations at each visit using Wilcoxon signed-rank test.

- Supplementary Table S5. Paired comparison of sputum supernatant metabolite concentrations at each visit using Wilcoxon signed-rank test.

- Supplementary Table S6. Pearson's correlations between metabolites among serum, urine, EBC, and sputum supernatant (attached as excel file).

- Supplementary Figure S1. Boxplots for the significant metabolites in all biofluids. 
Supplementary Table 1. Classification parameters for statistically significant comparisons among different pharmacological treatments from visit 1 to visit 4 based on mPLS models built on urine, serum, EBC and sputum supernatant (SS) NMR spectroscopic data in 14 patients with COPD. For each model the number of mPLS components used, accuracy, P-value, Youden's J, R2, Q2 are reported.

\begin{tabular}{|c|c|c|c|c|}
\hline Vs. & Visit 1 & Visit 2 & Visit 3 & Visit 4 \\
\hline Visit 1 & I & $\begin{array}{c}\text { Urine NOESY } \\
\text { NC }=16 \\
\text { Acc. }=71.0 \% \\
(P<0.05) \\
\text { Youden's J }=0.42 \\
\mathrm{R}^{2}=0.85 \\
\mathrm{Q}^{2}=0.44 \\
\text { Serum NOESY } \\
\mathrm{NC}=15 \\
\text { Acc. }=77.5 \% \\
(\mathrm{P}<0.05) \\
\text { Youden's } \mathrm{J}=0.55 \\
\mathrm{R}^{2}=0.83 \\
\mathrm{Q}^{2}=0.52\end{array}$ & $\begin{array}{c}\text { Serum Diffusion } \\
\mathrm{NC}=13 \\
\text { Acc. }=75.0 \% \\
(P<0.05) \\
\text { Youden's } \mathrm{J}=0.50 \\
\mathrm{R}^{2}=0.95 \\
\mathrm{Q}^{2}=0.51\end{array}$ & $\begin{array}{c}\text { EBC NOESY } \\
\text { NC }=18 \\
\text { Acc. }=72.0 \% \\
(P<0.05) \\
\text { Youden's J }=0.44 \\
\mathrm{R}^{2}=0.73 \\
\mathrm{Q}^{2}=0.45\end{array}$ \\
\hline \multirow{4}{*}{ Visit 2} & \multirow{4}{*}{ I } & \multirow{4}{*}{ I } & & $\begin{array}{c}\text { Serum NOESY } \\
\text { NC }=12 \\
\text { Acc. }=95.3 \% \\
(P<0.05) \\
\text { Youden's J }=0.91 \\
\mathrm{R}^{2}=0.92 \\
\mathrm{Q}^{2}=0.71\end{array}$ \\
\hline & & & $\begin{array}{c}\text { Urine NOESY } \\
\text { NC }=2 \\
\text { Acc. }=70.0 \% \\
(P<0.05) \\
\text { Youden's } \mathrm{J}=0.40 \\
\mathrm{R}^{2}=0.93 \\
\mathrm{Q}^{2}=0.43\end{array}$ & $\begin{array}{c}\text { Serum CPMG } \\
\text { NC }=12 \\
\text { Acc. }=92.7 \% \\
(P<0.05) \\
\text { Youden's } \mathrm{J}=0.85 \\
\mathrm{R}^{2}=0.93 \\
\mathrm{Q}^{2}=0.64\end{array}$ \\
\hline & & & $\begin{array}{c}\text { SP NOESY } \\
\text { NC }=4 \\
\text { Acc. }=82.0 \% \\
(P<0.05) \\
\text { Youden's } \mathrm{J}=0.64 \\
\mathrm{R}^{2}=0.67 \\
\mathrm{Q}^{2}=0.45\end{array}$ & $\begin{array}{c}\text { Serum Diffusion } \\
\mathrm{NC}=13 \\
\text { Acc. }=72.0 \% \\
(P<0.05) \\
\text { Youden's } \mathrm{J}=0.44 \\
\mathrm{R}^{2}=0.92 \\
\mathrm{Q}^{2}=0.47\end{array}$ \\
\hline & & & & $\begin{array}{c}\text { SP NOESY } \\
\text { NC }=3 \\
\text { Acc. }=81.3 \% \\
(P<0.05) \\
\text { Youden's J }=0.63 \\
\mathrm{R}^{2}=0.56 \\
\mathrm{Q}^{2}=0.46\end{array}$ \\
\hline Visit 3 & I & I & / & $\begin{array}{c}\text { Urine NOESY } \\
\text { NC }=7 \\
\text { Acc. }=71.6 \% \\
(P<0.05) \\
\text { Youden's } \mathrm{J}=0.43 \\
\mathrm{R}^{2}=0.87 \\
\mathrm{Q}^{2}=0.45\end{array}$ \\
\hline
\end{tabular}


Supplementary Table 2. Paired comparison of serum metabolite concentrations at each visit using Wilcoxon signed-rank test. Metabolite concentrations are reported as median arbitrary units \pm median absolute deviation (MAD) in arbitrary units. Statistically significant $P$-values $<0.05$ are shown in bold

\begin{tabular}{|c|c|c|c|c|c|c|c|c|c|c|}
\hline & Visit 1 & Visit 2 & Visit 3 & Visit 4 & 1 vs. 2 & 1 vs. 3 & 1 vs. 4 & 2 vs. 3 & 2 vs. 4 & 3 vs. 4 \\
\hline 3-hydroxybutyrate & $207 \pm 123$ & $275 \pm 277$ & $250 \pm 194$ & $239 \pm 247$ & 0.83 & 0.38 & 0.73 & 0.64 & 0.89 & 0.12 \\
\hline Acetate & $127 \pm 58$ & $94 \pm 41$ & $112 \pm 57$ & $142 \pm 92$ & 0.15 & 0.27 & 0.57 & 0.50 & 0.31 & 0.09 \\
\hline Acetoacetate & $156 \pm 88$ & $164 \pm 153$ & $144 \pm 113$ & $174 \pm 124$ & 1.00 & 0.23 & 0.97 & 0.31 & 0.95 & 0.04 \\
\hline Alanine & $3882 \pm 526$ & $3911 \pm 594$ & $3888 \pm 555$ & $3730 \pm 508$ & 0.32 & 0.52 & 0.52 & 0.69 & 0.50 & 0.50 \\
\hline Citrate & $387 \pm 76$ & $407 \pm 123$ & $438 \pm 169$ & $385 \pm 133$ & 0.21 & 0.11 & 0.68 & 0.59 & 0.27 & 0.10 \\
\hline Creatine & $98 \pm 48$ & $119 \pm 37$ & $105 \pm 50$ & $125 \pm 53$ & 1.00 & 0.34 & 0.68 & 1.00 & 0.79 & 0.50 \\
\hline Creatinine & $473 \pm 128$ & $491 \pm 119$ & $461 \pm 145$ & $492 \pm 199$ & 0.12 & 0.34 & 0.97 & 0.89 & 0.41 & 0.12 \\
\hline Formate & $31 \pm 8$ & $39 \pm 20$ & $42 \pm 14$ & $32 \pm 17$ & 0.12 & 0.03 & 0.91 & 0.50 & 0.17 & 0.17 \\
\hline Glucose & $8326 \pm 838$ & $8360 \pm 1271$ & $8644 \pm 1618$ & $7917 \pm 1774$ & 0.41 & 0.57 & 0.34 & 0.74 & 0.59 & 0.19 \\
\hline Glutamate & $566 \pm 70$ & $543 \pm 154$ & $567 \pm 55$ & $638 \pm 65$ & 0.90 & 0.85 & 0.27 & 0.54 & 0.79 & 0.86 \\
\hline Glutamine & $4447 \pm 624$ & $4906 \pm 531$ & $4412 \pm 781$ & $4194 \pm 1084$ & 0.04 & 0.73 & 0.68 & 0.50 & 0.04 & 0.03 \\
\hline Glycerol & $733 \pm 119$ & $702 \pm 170$ & $714 \pm 199$ & $690 \pm 162$ & 0.32 & 0.15 & 0.27 & 0.64 & 0.79 & 0.86 \\
\hline Glycine & $1048 \pm 183$ & $1087 \pm 266$ & $1013 \pm 285$ & $985 \pm 336$ & 0.21 & 0.79 & 0.42 & 0.19 & 0.02 & 0.19 \\
\hline Histidine & $263 \pm 47$ & $288 \pm 53$ & $303 \pm 73$ & $305 \pm 58$ & 0.41 & 0.73 & 0.91 & 0.24 & 0.69 & 0.86 \\
\hline Isoleucine & $296 \pm 77$ & $299 \pm 43$ & $303 \pm 73$ & $312 \pm 58$ & 0.83 & 0.73 & 0.52 & 0.79 & 0.15 & 0.19 \\
\hline Lactate & $2321 \pm 830$ & $2489 \pm 1163$ & $2358 \pm 638$ & $2226 \pm 364$ & 0.90 & 0.91 & 0.79 & 0.69 & 0.15 & 0.14 \\
\hline Leucine & $920 \pm 212$ & $881 \pm 75$ & $875 \pm 209$ & $947 \pm 132$ & 0.90 & 0.52 & 0.79 & 0.89 & 0.50 & 0.54 \\
\hline Mannose & $167 \pm 30$ & $168 \pm 19$ & $175 \pm 16$ & $165 \pm 33$ & 0.52 & 0.15 & 0.15 & 0.05 & 0.74 & 0.07 \\
\hline Phenylalanine & $522 \pm 81$ & $461 \pm 54$ & $496 \pm 67$ & $504 \pm 88$ & 0.15 & 0.79 & 0.79 & 0.10 & 0.41 & 0.95 \\
\hline Proline & $164 \pm 62$ & $162 \pm 49$ & $146 \pm 43$ & $161 \pm 45$ & 0.97 & 0.13 & 0.91 & 0.19 & 0.59 & 0.07 \\
\hline Pyruvate & $413 \pm 140$ & $455 \pm 89$ & $431 \pm 252$ & $409 \pm 192$ & 0.58 & 0.91 & 0.73 & 0.89 & 0.34 & 0.72 \\
\hline Threonine+Lactate & $21526 \pm 7289$ & $22247 \pm 9198$ & $21529 \pm 5028$ & $20461 \pm 3277$ & 1.00 & 0.91 & 0.79 & 0.74 & 0.17 & 0.10 \\
\hline Tyrosine & $509 \pm 106$ & $473 \pm 80$ & $482 \pm 101$ & $510 \pm 144$ & 0.83 & 0.23 & 0.79 & 0.27 & 0.84 & 0.19 \\
\hline Valine & $2937 \pm 530$ & $2759 \pm 230$ & $2682 \pm 566$ & $2739 \pm 385$ & 0.83 & 0.23 & 0.57 & 0.31 & 0.84 & 0.76 \\
\hline
\end{tabular}


Supplementary Table 3. Paired comparison of urinary metabolite concentrations at each visit using Wilcoxon signed-rank test. Metabolite concentrations are reported as median arbitrary units \pm median absolute deviation (MAD). Statistically significant $P$-values $<0.05$ are shown in bold.

\begin{tabular}{|c|c|c|c|c|c|c|c|c|c|c|}
\hline & Visit 1 & Visit 2 & Visit 3 & Visit 4 & 1 vs. 2 & 1 vs. 3 & 1 vs. 4 & 2 vs. 3 & 2 vs. 4 & 3 vs. 4 \\
\hline$\overline{\text { Alanine }}$ & $408 \pm 103$ & $385 \pm 102$ & $423 \pm 86$ & $421 \pm 167$ & 0.670 & 0.855 & 0.296 & 0.104 & 0.119 & 0.502 \\
\hline cis-Aconitate & $351 \pm 106$ & $348 \pm 131$ & $314 \pm 171$ & $299 \pm 151$ & 0.903 & 0.855 & 0.296 & 0.426 & 0.463 & 0.502 \\
\hline Citrate & $7479 \pm 3528$ & $6576 \pm 3913$ & $7807 \pm 4876$ & $6091 \pm 3151$ & 0.153 & 0.502 & 0.241 & 0.761 & 0.903 & 0.855 \\
\hline Creatinine & $35963 \pm 6183$ & $36142 \pm 6792$ & $34720 \pm 6096$ & $31391 \pm 4800$ & 0.119 & 0.583 & 0.502 & 0.173 & $0.007 *$ & 0.502 \\
\hline Glycine & $2168 \pm 652$ & $1820 \pm 731$ & $2478 \pm 902$ & $2296 \pm 818$ & 0.268 & 1.000 & 0.761 & 0.049 & 0.058 & 0.583 \\
\hline Hippurate & $11102 \pm 3572$ & $10223 \pm 4288$ & $9849 \pm 3353$ & $11048 \pm 3364$ & 0.426 & 0.391 & 0.626 & 0.855 & 0.952 & 0.078 \\
\hline Isobutyrate & $160 \pm 63$ & $160 \pm 46$ & $167 \pm 51$ & $187 \pm 44$ & 0.296 & 1.000 & 0.268 & 0.583 & $0.004 *$ & 0.808 \\
\hline Leucine & $86 \pm 21$ & $77 \pm 24$ & $83 \pm 15$ & $93 \pm 38$ & 0.268 & 0.903 & 0.173 & 0.194 & 0.011 & 0.296 \\
\hline 1-Methylnicotinamide & $59 \pm 28$ & $54 \pm 21$ & $50 \pm 23$ & $73 \pm 35$ & 0.855 & 0.042 & 0.135 & 0.091 & 0.542 & $0.002 *$ \\
\hline Phenylacetylglycine & $6666 \pm 1995$ & $6166 \pm 2182$ & $5957 \pm 2139$ & $5861 \pm 1577$ & 0.903 & 0.903 & 0.583 & 0.583 & 0.296 & 0.670 \\
\hline p-Hydroxyphenylacetate & $259 \pm 63$ & $230 \pm 33$ & $252 \pm 53$ & $245 \pm 100$ & 0.542 & 0.903 & 1.000 & 0.855 & 0.583 & 1.000 \\
\hline Pyruvate & $3805 \pm 1455$ & $3390 \pm 1952$ & $4229 \pm 1761$ & $3096 \pm 1088$ & 0.761 & 0.583 & 0.173 & 0.808 & 0.463 & 0.715 \\
\hline Trigonelline & $1490 \pm 225$ & $1345 \pm 275$ & $1637 \pm 434$ & $1787 \pm 549$ & 0.715 & 0.463 & 0.268 & 0.358 & 0.296 & 0.903 \\
\hline Trimethylamine & $417 \pm 159$ & $373 \pm 158$ & $421 \pm 153$ & $412 \pm 129$ & 0.217 & 0.583 & 0.426 & 0.005 & 0.542 & 0.173 \\
\hline Valine & $77 \pm 19$ & $77 \pm 24$ & $76 \pm 15$ & $70 \pm 20$ & 0.583 & 0.855 & 0.626 & 0.463 & 1.000 & 0.502 \\
\hline
\end{tabular}


Supplementary Table 4. Paired comparison of exhaled breath condensate (EBC) metabolite concentrations at each visit using Wilcoxon signed-rank test. Metabolite concentrations are reported as median arbitrary units \pm median absolute deviation (MAD). Statistically significant $P$-values $<0.05$ are shown in bold. These results were previously published (Montuschi et al.; Front. Pharmacol. 2018).

\begin{tabular}{lcccccccccc}
\hline & Visit 1 & Visit 2 & Visit 3 & Visit 4 & 1 vs 2 1 vs 3 1 vs 4 & 2 vs 3 & 2 vs 4 & 3 vs 4 \\
\hline Acetate & $7323 \pm 3372$ & $8635 \pm 6598$ & $10385 \pm 4930$ & $4683 \pm 1519$ & 0.95 & 0.33 & 0.33 & 0.95 & 0.12 & $\mathbf{0 . 0 1}$ \\
Acetoin & $706 \pm 483$ & $512 \pm 216$ & $731 \pm 311$ & $546 \pm 360$ & 0.12 & 0.54 & 0.27 & 0.09 & 0.54 & 0.12 \\
Acetone & $6152 \pm 3456$ & $6073 \pm 1730$ & $6850 \pm 2421$ & $6579 \pm 2469$ & 0.81 & 1.00 & 0.22 & 0.58 & 0.63 & 0.17 \\
3-Hydroxyisovalerate & $326 \pm 65$ & $351 \pm 46$ & $388 \pm 44$ & $377 \pm 89$ & 0.71 & 0.30 & 0.58 & 0.33 & 0.81 & 0.33 \\
Ethanol & $488 \pm 100$ & $539 \pm 202$ & $754 \pm 385$ & $545 \pm 239$ & 1.00 & 0.06 & 0.95 & 0.39 & 0.95 & 0.08 \\
Formate & $695 \pm 360$ & $695 \pm 520$ & $425 \pm 132$ & $409 \pm 225$ & 0.86 & 0.67 & $\mathbf{0 . 0 3}$ & 0.17 & 0.05 & 0.05 \\
Lactate & $444 \pm 159$ & $284 \pm 92$ & $353 \pm 142$ & $289 \pm 115$ & 0.95 & 0.95 & 0.12 & 0.95 & 0.12 & 0.30 \\
Leucine/n-butyrate & $1432 \pm 482$ & $2484 \pm 1743$ & $2002 \pm 896$ & $1584 \pm 538$ & 0.50 & 0.12 & 0.67 & 0.71 & 0.12 & 0.06 \\
Methanol & $14225 \pm 7045$ & $16269 \pm 7711$ & $11571 \pm 2751$ & $14359 \pm 8342$ & 1.00 & 0.36 & 0.95 & 0.81 & 0.63 & 0.67 \\
n-butyrate & $664 \pm 199$ & $1573 \pm 1205$ & $1099 \pm 469$ & $767 \pm 252$ & 0.22 & 0.14 & 0.86 & 0.71 & 0.12 & 0.17 \\
Phenol & $443 \pm 225$ & $326 \pm 204$ & $354 \pm 158$ & $336 \pm 204$ & 0.22 & 0.76 & 0.36 & 0.07 & 0.63 & 0.39 \\
Propionate & $1543 \pm 740$ & $2395 \pm 1967$ & $2520 \pm 1755$ & $988 \pm 706$ & 0.46 & 0.12 & 0.58 & 0.46 & 0.46 & 0.09 \\
Trimethylamine & $365 \pm 261$ & $344 \pm 262$ & $348 \pm 211$ & $302 \pm 196$ & 0.76 & 0.36 & 0.86 & 0.39 & 0.90 & 0.46 \\
\hline
\end{tabular}


Supplementary Table 5. Paired comparison of sputum supernatant metabolite concentrations at each visit using Wilcoxon signed-rank test. Metabolite concentrations are reported as median arbitrary units \pm median absolute deviation (MAD). Statistically significant $P$-values $<0.05$ are shown in bold.

\begin{tabular}{lcccccccccccc}
\hline & Visit 1 & Visit 2 & Visit 3 & Visit 4 & 1 vs. 2 & 1 vs. 3 & 1 vs. 4 & 2 vs. 3 & 2 vs. 4 & 3 vs. 4 \\
\hline Acetate & $2786 \pm 1862$ & $3426 \pm 3678$ & $1909 \pm 1196$ & $2098 \pm 1196$ & 0.50 & 0.22 & 0.24 & $\mathbf{0 . 0 0 5}$ & 0.08 & 0.54 \\
Acetoin & $74 \pm 46$ & $45 \pm 40$ & $73 \pm 73$ & $99 \pm 73$ & 0.08 & 0.15 & 0.43 & $\mathbf{0 . 0 2}$ & $\mathbf{0 . 0 3}$ & 0.71 \\
Acetone & $206 \pm 77$ & $237 \pm 194$ & $268 \pm 167$ & $190 \pm 167$ & 0.33 & $\mathbf{0 . 0 4}$ & 0.67 & 0.71 & 1.00 & 0.62 \\
Alanine & $133 \pm 67$ & $87 \pm 33$ & $117 \pm 67$ & $42 \pm 67$ & 0.43 & 0.17 & 0.10 & 0.45 & $\mathbf{0 . 0 5}$ & 0.29 \\
Formate & $80 \pm 57$ & $80 \pm 35$ & $119 \pm 41$ & $105 \pm 41$ & 0.62 & 0.26 & 0.76 & 0.54 & 0.39 & 0.90 \\
Glycine & $200 \pm 138$ & $177 \pm 147$ & $115 \pm 70$ & $193 \pm 70$ & 0.90 & 0.17 & 0.39 & 0.36 & 0.46 & 0.53 \\
Lactate & $1244 \pm 626$ & $1390 \pm 432$ & $1722 \pm 1484$ & $1282 \pm 1484$ & 0.39 & 0.78 & 0.78 & 0.71 & 0.86 & 0.44 \\
Propionate & $107 \pm 82$ & $85 \pm 82$ & $46 \pm 58$ & $90 \pm 58$ & 0.43 & 0.19 & 0.07 & $\mathbf{0 . 0 3}$ & 0.19 & 0.94 \\
Taurine & $259 \pm 191$ & $292 \pm 181$ & $264 \pm 154$ & $290 \pm 154$ & 0.81 & 0.46 & 0.81 & 0.81 & 0.94 & 0.95 \\
Unknown & $240795 \pm 149320$ & $156930 \pm 167664$ & $362755 \pm 420484$ & $295268 \pm 420484$ & 0.81 & 0.06 & 0.29 & 0.12 & 0.06 & 0.90 \\
\hline
\end{tabular}


Supplementary Figure S1. Boxplots for statistically significant comparisons among different pharmacological treatments from visit 1 to visit 4 based on mPLS models built on urine, serum, EBC and sputum supernatant (SS) NMR spectroscopic data in 14 patients with COPD.
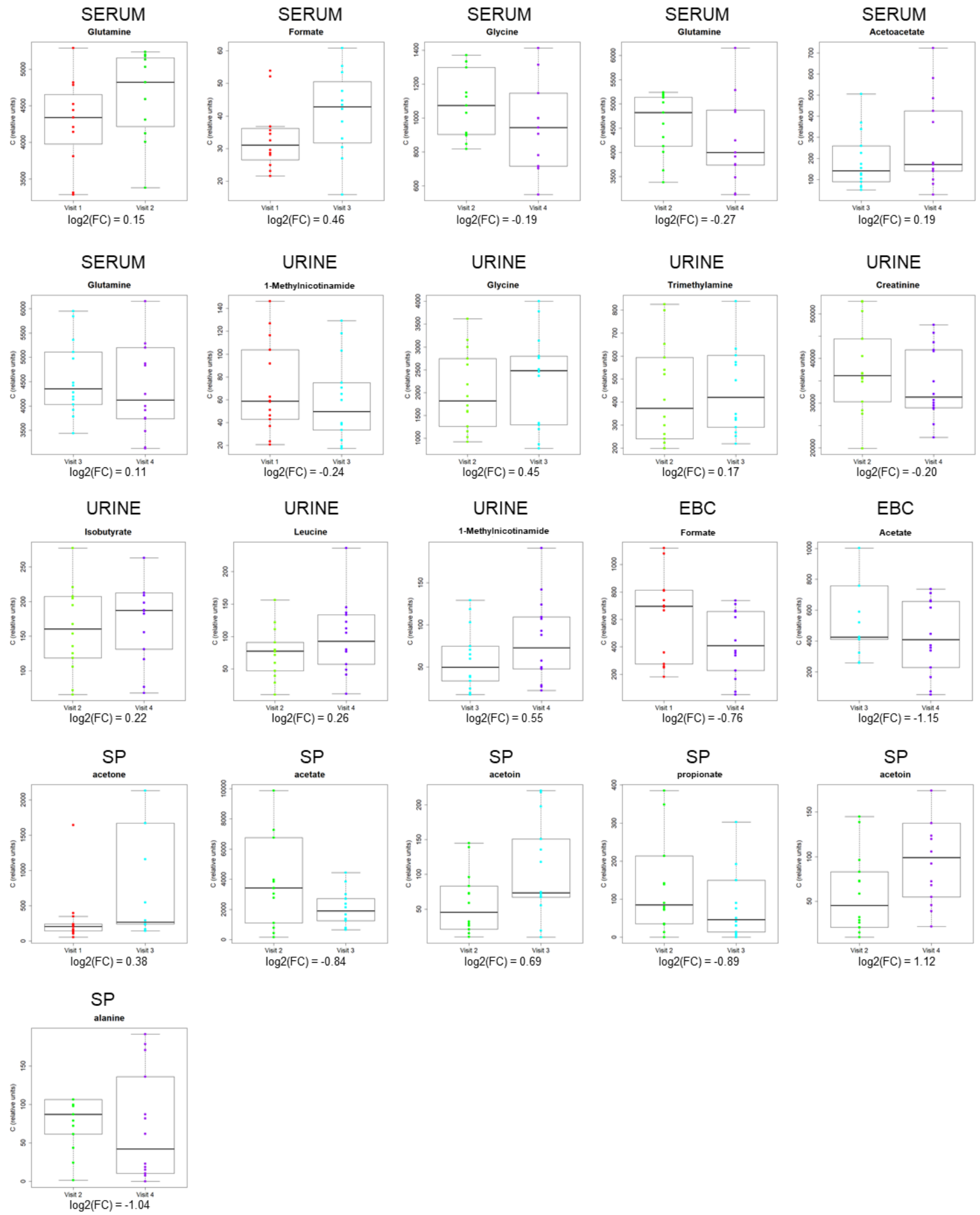
Supplementary Table S6. Pearson's correlations between metabolites among ser

Urine_Leucine
Urine_Valine
Urine_Isobutyrate
Urine_Alanine
Urine_Pyruvate
Urine_Citrate
Urine_Trimethyamine
Urine_Glycine
Urine_Creatinine
Urine_Trigonelline
Urine_cis.Aconitate

Urine_p.Hydroxyphenylacetate Urine_Phenylacetylglycine

Urine_Hippurate

Urine_Methylnicotinamide

Serum_Formate

Serum_Phenylalanine

Serum_Histidine

Serum_Tyrosine

Serum_Glucose

Serum_Mannose

Serum_Proline

Serum_Lactate

Serum_Creatinine

Serum_Creatine

Serum_Glycerol

Serum_Glycine

Serum_Citrate

Serum_Glutamine

Serum_Glutamate

Serum_Pyruvate

Serum_Acetoacetate

Serum_Acetate

Serum_Alanine

Serum_Threonine.Lactate

Serum_3.hydroxybutyrate

Serum_Valine

Serum_Isoleucine

Serum_Leucine

Sputum_propionato

Sputum_lactate

Sputum_acetoin

Sputum_alanine

Sputum_acetate

Sputum_acetone

Sputum_succinate

Sputum_unk

Sputum_taurine

Sputum_glycine
Urine_Leucine Urine_Valine Urine_Isobutyrate Urine_Alanine

\begin{tabular}{|c|c|c|c|}
\hline 1 & 0,563425097 & 0,525824172 & 0,574132491 \\
\hline 5097 & 1 & 0,740082922 & 0,587569349 \\
\hline 0,525824172 & 0,740082922 & 1 & 0,697473181 \\
\hline 0,574132491 & 0,587569349 & 0,697473181 & \\
\hline$-0,115058974$ & $-0,232553867$ & $-0,273591039$ & $-0,073044995$ \\
\hline 0,278289659 & 0,516134315 & 0,644653934 & 0,55388655 \\
\hline 0,450830673 & 0,163488981 & $-0,067277024$ & $-0,056003775$ \\
\hline 0,501334947 & 0,637572939 & 0,442416899 & 0,411448415 \\
\hline 0,480549142 & 0,584282273 & 0,342671644 & 0,273305661 \\
\hline 0,001467482 & $-0,141791004$ & $-0,061067886$ & $-0,031615375$ \\
\hline 0,241942599 & 0,369631239 & $-0,071628794$ & 0,055747016 \\
\hline 0,325795837 & 0,266540832 & 0,093661665 & 0,217200584 \\
\hline$-0,020249511$ & $-0,237182987$ & $-0,28310163$ & $-0,036213069$ \\
\hline 0,004850229 & $-0,071957594$ & $-0,084104306$ & 0,11725234 \\
\hline 0,017643005 & 0,314723638 & 0,212392292 & $-0,174366706$ \\
\hline$-0,080681182$ & $-0,289883954$ & 0,033412082 & $-0,003902$ \\
\hline 0,096697004 & $-0,179007981$ & $-0,315524503$ & $-0,222588104$ \\
\hline$-0,199709988$ & $-0,306507247$ & $-0,264595917$ & $-0,48913$ \\
\hline 0,133774594 & $-0,126314407$ & $-0,141751124$ & $-0,086525$ \\
\hline$-0,105390893$ & 0,133787329 & $-0,110286514$ & 0,001752475 \\
\hline$-0,033444278$ & 0,139990571 & $-0,056498107$ & 0,109865261 \\
\hline 0,020228743 & $-0,010500762$ & $-0,074095401$ & $-0,141520349$ \\
\hline$-0,069959393$ & 0,084156221 & $-0,106496254$ & $-0,287596602$ \\
\hline$-0,232607673$ & $-0,459942583$ & $-0,628370652$ & $-0,360298057$ \\
\hline 0,129911259 & 0,035753292 & 0,107348903 & $-0,0760336$ \\
\hline$-0,246018745$ & $-0,410661261$ & $-0,387425318$ & $-0,406872993$ \\
\hline$-0,285560055$ & $-0,388180979$ & $-0,593821148$ & $-0,648952234$ \\
\hline 0,014799426 & $-0,280128729$ & $-0,19859416$ & $-0,2202 \epsilon$ \\
\hline$-0,399312114$ & $-0,527392747$ & $-0,473107561$ & $-0,582770$ \\
\hline 0,05679742 & 0,142257482 & $-0,023702619$ & 0,041139 \\
\hline 0,030925488 & 0,26420332 & $-0,031413305$ & 0,031949772 \\
\hline$-0,101339739$ & 0,025067191 & 0,029711112 & $-0,133774758$ \\
\hline 0,23028259 & $-0,099026049$ & 0,076300721 & 0,2133756 \\
\hline$-0,122399228$ & $-0,11181882$ & $-0,356770594$ & $-0,280817126$ \\
\hline$-0,076254979$ & 0,064147553 & $-0,122125068$ & $-0,328913164$ \\
\hline$-0,08546291$ & $-0,035825879$ & 0,035418461 & $-0,136353932$ \\
\hline 0,125195209 & 0,126099239 & $-0,163099445$ & $-0,216943005$ \\
\hline 0,473472805 & 0,136379404 & $-0,013094146$ & 0,125233537 \\
\hline 0,240260243 & 0,019352954 & $-0,226767042$ & $-0,159059393$ \\
\hline 0,167362084 & 0,027962543 & $-0,008591784$ & $-0,034984725$ \\
\hline$-0,026477288$ & 0,227942625 & 0,084272811 & 0,107447311 \\
\hline 0,144526198 & 0,079956151 & 0,301920419 & 0,013385132 \\
\hline$-0,096985078$ & $-0,145957388$ & $-0,450299595$ & $-0,156984526$ \\
\hline 0,004573839 & 0,016916734 & $-0,087685936$ & $-0,074788835$ \\
\hline$-0,105971794$ & $-0,013892743$ & 0,024358254 & $-0,121344843$ \\
\hline 0,106467691 & 0,233378905 & 0,085878999 & 0,202811061 \\
\hline 0,103370334 & 0,087239348 & 0,341340572 & 0,075963831 \\
\hline$-0,164989698$ & $-0,02432712$ & $-0,00250079$ & $-0,136944042$ \\
\hline$-0,193479667$ & $-0,083288917$ & $-0,078782161$ & $-0,030762078$ \\
\hline
\end{tabular}




Sputum_formate
EBC_Leucine.n.butyrate
EBC_Propionate
EBC_Ethanol
EBC_3.hydroxyisovalerate
EBC_Lactate
EBC_Acetoine
EBC_n.Butyrate
EBC_Acetate
EBC_Acetone
EBC_Trimethylamine
EBC_Methanol
EBC_Phenol
EBC_Formate

$\begin{array}{rrrr}-0,033868192 & -0,062490945 & -0,034076474 & -0,133300712 \\ 0,143248807 & 0,128917011 & -0,104581562 & 0,149437094 \\ 0,230240514 & 0,145754956 & -0,119454172 & 0,223543097 \\ 0,155596588 & 0,210342952 & -0,049856551 & -0,032134361 \\ -0,009653255 & 0,041466074 & -0,221842898 & -0,07444936 \\ -0,153614842 & -0,02116696 & -0,284917091 & -0,136611055 \\ -0,018061341 & -0,063759586 & 0,018238863 & -0,035399585 \\ 0,061812172 & 0,087056071 & -0,138980484 & 0,10201256 \\ 0,058671932 & 0,058837161 & -0,117208072 & 0,155207047 \\ -0,099828463 & 0,012281395 & -0,148087977 & -0,098121429 \\ 0,297597699 & -0,003201564 & -0,138587536 & 0,110774572 \\ -0,205428 & 0,015392546 & -0,195228139 & -0,177915312 \\ 0,394915689 & 0,268499611 & -0,030610535 & 0,076380321 \\ -0,055857333 & 0,034633121 & -0,110241687 & 0,025537282\end{array}$


\lrcorner $\mathrm{m}$, urine, EBC, and sputum supernatant

\begin{tabular}{|c|c|c|c|c|}
\hline Urine_Pyruvate & Urine_Citrate & Urine_Trimethyamine & Urine_Glycine & Urine_Creatinine \\
\hline$-0,115058974$ & 0,278289659 & 0,450830673 & 0,501334947 & 0,480549142 \\
\hline$-0,232553867$ & 0,516134315 & 0,163488981 & 0,637572939 & 0,584282273 \\
\hline$-0,273591039$ & 0,644653934 & $-0,067277024$ & 0,442416899 & 0,342671644 \\
\hline$-0,073044995$ & 0,55388655 & $-0,056003775$ & 0,411448415 & 0,273305661 \\
\hline 1 & $-0,061961494$ & 0,29333339 & $-0,100377311$ & $-0,242811149$ \\
\hline$-0,061961494$ & 1 & $-0,140697581$ & 0,615135467 & 0,39948712 \\
\hline 0,29333339 & $-0,140697581$ & 1 & 0,329870717 & 0,384378781 \\
\hline$-0,100377311$ & 0,615135467 & 0,329870717 & 1 & 0,564810517 \\
\hline$-0,242811149$ & 0,39948712 & 0,384378781 & 0,564810517 & 1 \\
\hline 0,081032377 & 0,091361308 & 0,148777363 & 0,054293455 & 0,094637233 \\
\hline 0,009529281 & $-0,135378656$ & 0,426972255 & 0,275994066 & 0,459563971 \\
\hline$-0,087184419$ & 0,047221392 & 0,160481689 & 0,245518372 & 0,132592412 \\
\hline 0,836676498 & $-0,182475515$ & 0,312263508 & $-0,109204882$ & $-0,287050468$ \\
\hline 0,337008332 & $-0,056226244$ & 0,017246382 & 0,000871255 & $-0,170823659$ \\
\hline$-0,488040212$ & 0,273605746 & $-0,082846259$ & 0,379140193 & 0,463582259 \\
\hline 0,061062769 & 0,016803171 & $-0,093498541$ & $-0,234258405$ & $-0,377537118$ \\
\hline 0,133720885 & $-0,247466011$ & 0,445636578 & 0,072308349 & $-0,035220136$ \\
\hline 0,272802296 & $-0,33284466$ & 0,120286624 & $-0,113855423$ & $-0,126884211$ \\
\hline$-0,155299711$ & $-0,045150807$ & 0,173062836 & 0,082644429 & 0,031696533 \\
\hline$-0,015095424$ & - $-0,019517961$ & 0,114996962 & 0,18860556 & $-0,088179831$ \\
\hline 0,106196011 & $-0,02874858$ & 0,044818358 & $-0,002104631$ & $-0,14141067$ \\
\hline 0,151655676 & $-0,299321473$ & 0,188971881 & 0,084578183 & $-0,162826537$ \\
\hline$-0,113947031$ & $-0,328705436$ & 0,041040991 & $-0,203620276$ & 0,049013338 \\
\hline 0,493877187 & $-0,664553674$ & 0,286293945 & $-0,565493823$ & $-0,30679392$ \\
\hline$-0,106756523$ & 0,273912533 & 0,033859539 & 0,251311388 & 0,325236031 \\
\hline 0,121938634 & - $-0,180589734$ & $-0,088725717$ & $-0,184235525$ & $-0,234588938$ \\
\hline 0,249065015 & $-0,455202798$ & 0,117192588 & $-0,283864319$ & $-0,065390765$ \\
\hline 0,380746634 & - $-0,085433777$ & 0,260483674 & $-0,113947233$ & $-0,049959348$ \\
\hline 0,397134968 & $-0,469713943$ & 0,004675963 & $-0,403101641$ & $-0,406412204$ \\
\hline$-0,098374665$ & $-0,250755697$ & 0,152364973 & 0,101164055 & 0,012226133 \\
\hline$-0,024906516$ & 0,030302395 & 0,155136676 & 0,039333522 & 0,241690582 \\
\hline$-0,057109825$ & $-0,138756427$ & $-0,059204708$ & 0,052706914 & $-0,163498333$ \\
\hline 0,088047014 & $-0,09109013$ & 0,044657898 & $-0,068182943$ & $-0,31845781$ \\
\hline 0,263347471 & $-0,1516697$ & 0,304575376 & $-0,048068192$ & 0,036558416 \\
\hline$-0,120953857$ & $-0,346396355$ & 0,036998636 & $-0,211773198$ & 0,043452027 \\
\hline 0,114560585 & $-0,102447163$ & 0,01526984 & 0,009881483 & $-0,220427441$ \\
\hline$-0,104932403$ & $-0,26009338$ & 0,29608467 & 0,157454047 & 0,321988041 \\
\hline$-0,052656047$ & $-0,056026635$ & 0,393648215 & 0,190280017 & 0,265813678 \\
\hline 0,011708631 & $-0,257221216$ & 0,417093601 & 0,087916751 & 0,173626046 \\
\hline$-0,014452614$ & 0,043511123 & 0,338270206 & 0,120642451 & 0,36990193 \\
\hline 0,080370245 & 0,064419381 & 0,100077226 & 0,11018073 & 0,185758495 \\
\hline$-0,289264362$ & 0,192454658 & $-0,033046436$ & 0,153170994 & 0,04315247 \\
\hline 0,103866952 & $-0,477205255$ & 0,08839145 & $-0,339633089$ & $-0,184874092$ \\
\hline$-0,060845305$ & $-0,066760099$ & 0,183880338 & 0,026068883 & 0,280706854 \\
\hline$-0,235099132$ & $-0,042495369$ & $-0,15827108$ & $-0,153722679$ & 0,021242668 \\
\hline 0,131051924 & 0,114743135 & 0,035742505 & 0,333838459 & 0,105692828 \\
\hline$-0,341776333$ & 0,170352898 & $-0,205210828$ & 0,007407079 & 0,14029394 \\
\hline$-0,144040725$ & $-0,126924443$ & $-0,143478116$ & $-0,190707737$ & 0,112299894 \\
\hline 0,150854376 & $-0,027260358$ & $-0,11271591$ & $-0,083934341$ & $-0,215612998$ \\
\hline
\end{tabular}




$\begin{array}{rrrrr}0,04645023 & -0,132179569 & 0,007618277 & -0,026280243 & -0,145423451 \\ 0,153467976 & -0,019659863 & 0,149303035 & 0,105995859 & 0,143648664 \\ 0,16957649 & -0,062902736 & 0,140465843 & 0,095320418 & 0,182474912 \\ -0,080016089 & -0,071440859 & -0,043061242 & 0,043857467 & 0,320143657 \\ 0,165599727 & -0,072378514 & -0,031671943 & -0,095323679 & -0,011547929 \\ 0,39482375 & -0,012659507 & 0,228938972 & 0,152476355 & 0,060937094 \\ 0,004641835 & 0,026050699 & -0,116757887 & -0,043708743 & -0,121073224 \\ 0,178375069 & -0,036481894 & 0,073088956 & 0,061469194 & 0,082530576 \\ 0,129683475 & -0,06582845 & 0,006967268 & 0,00884082 & 0,009803816 \\ 0,224812875 & -0,06245979 & -0,102542934 & -0,038834513 & -0,110640324 \\ 0,105759653 & -0,06720949 & 0,420694725 & 0,134161868 & 0,264264056 \\ 0,157112548 & 0,079439523 & -0,010490143 & -0,049795168 & -0,140215833 \\ -0,011083881 & 0,084250022 & 0,410627547 & 0,199474836 & 0,447139021 \\ 0,205209346 & -0,02979788 & 0,096546285 & 0,051887289 & 0,034324945\end{array}$




\begin{tabular}{|c|c|c|c|}
\hline rine_Trigonelline & Urine_cis.Aconitate & Urine_p.Hydroxyphenylacetate & Urine_Phenylacetylglycine \\
\hline 0,001467482 & 0,241942599 & 0,325795837 & $-0,020249511$ \\
\hline$-0,141791004$ & 0,369631239 & 0,266540832 & $-0,237182987$ \\
\hline$-0,061067886$ & $-0,071628794$ & 0,093661665 & $-0,28310163$ \\
\hline$-0,031615375$ & 0,055747016 & 0,217200584 & $-0,036213069$ \\
\hline 0,081032377 & 0,009529281 & $-0,087184419$ & 0,836676498 \\
\hline 0,091361308 & $-0,135378656$ & 0,047221392 & $-0,182475515$ \\
\hline 0,148777363 & 0,426972255 & 0,160481689 & 0,312263508 \\
\hline 0,054293455 & 0,275994066 & 0,245518372 & $-0,109204882$ \\
\hline 0,094637233 & 0,459563971 & 0,132592412 & $-0,287050468$ \\
\hline 1 & $-0,234571281$ & 0,099525316 & 0,155544358 \\
\hline$-0,234571281$ & 1 & 0,276565845 & 0,047009121 \\
\hline 0,099525316 & 0,276565845 & 1 & 0,039994232 \\
\hline 0,155544358 & 0,047009121 & 0,039994232 & ( \\
\hline$-0,380932817$ & 0,124313238 & $-0,130495068$ & 0,130425716 \\
\hline 0,130713995 & $-0,042522382$ & 0,065651718 & $-0,500549542$ \\
\hline 0,037126767 & $-0,364728496$ & 0,042896317 & 0,079620305 \\
\hline$-0,082752062$ & 0,12638587 & $-0,028414503$ & 0,060444525 \\
\hline 0,068219582 & $-0,047093906$ & $-0,11236972$ & 0,170538984 \\
\hline$-0,080407668$ & $-0,076536557$ & $-0,004937939$ & $-0,202702022$ \\
\hline 0,03227071 & 0,326565339 & 0,379385242 & 0,064429674 \\
\hline$-0,087717393$ & 0,331703205 & 0,253710793 & 0,171771538 \\
\hline$-0,174706167$ & 0,241458838 & 0,07577202 & 0,330350795 \\
\hline$-0,053807003$ & 0,359845868 & 0,056944387 & $-0,050545366$ \\
\hline 0,056278437 & 0,121599585 & $-0,209789591$ & 0,430562893 \\
\hline 0,422807655 & $-0,304053937$ & 0,08329282 & $-0,073988541$ \\
\hline 0,282196179 & $-0,351874904$ & $-0,014698328$ & 0,283153844 \\
\hline 0,077539503 & $-0,026188925$ & $-0,206978499$ & 0,157737093 \\
\hline 0,224076138 & $-0,195897807$ & $-0,179716738$ & 0,358633982 \\
\hline 0,113355863 & $-0,218792254$ & $-0,201475073$ & 0,346385351 \\
\hline$-0,265752629$ & 0,46216399 & 0,165590775 & 0,004896386 \\
\hline 0,010285122 & 0,488348024 & 0,086302756 & 0,016704383 \\
\hline$-0,104126628$ & 0,063506957 & $-0,019856265$ & 0,175550068 \\
\hline 0,037404194 & $-0,059049279$ & 0,230344129 & 0,241421577 \\
\hline$-0,181630351$ & 0,384172453 & $-0,019131715$ & 0,138275682 \\
\hline$-0,066984349$ & 0,344894667 & 0,038027721 & $-0,05850652$ \\
\hline$-0,125840085$ & 0,04859208 & $-0,026830618$ & 0,305879827 \\
\hline 0,010002686 & 0,381343268 & 0,137429753 & $-0,109689002$ \\
\hline 0,019084586 & 0,318975004 & 0,31043461 & $-0,072841551$ \\
\hline 0,018113628 & 0,375793779 & 0,235301194 & 0,019476627 \\
\hline 0,014032137 & 0,15647108 & 0,155432684 & 0,020912023 \\
\hline$-0,012908524$ & 0,311279752 & 0,298902906 & 0,004640738 \\
\hline 0,112212044 & $-0,184987461$ & 0,026368864 & $-0,38209428$ \\
\hline$-0,140362239$ & 0,144693997 & 0,076662417 & 0,054594102 \\
\hline$-0,102507657$ & 0,246042439 & 0,12726099 & $-0,019368477$ \\
\hline 0,039326595 & $-0,039426805$ & $-0,112740222$ & $-0,270203663$ \\
\hline$-0,157105542$ & 0,327785622 & 0,421838569 & 0,205557188 \\
\hline$-1,33 \mathrm{E}-05$ & $-0,203512441$ & $-0,062881409$ & $-0,423547566$ \\
\hline$-0,070883149$ & 0,145026273 & 0,023986632 & $-0,162924058$ \\
\hline$-0,029343191$ & 0,009552834 & 0,047877861 & 0,129312241 \\
\hline
\end{tabular}




$\begin{array}{rr}-0,173703762 & -0,012030201 \\ -0,027299643 & 0,252617524 \\ -0,101171208 & 0,281775418 \\ 0,000341475 & 0,216896874 \\ -0,039028406 & 0,189373761 \\ -0,077690866 & 0,202493871 \\ -0,175993297 & -0,168497034 \\ -0,035536854 & 0,23302637 \\ -0,06001886 & 0,158790637 \\ -0,149215656 & 0,193979706 \\ 0,081597205 & 0,108076126 \\ -0,066063774 & 0,130371845 \\ 0,119825089 & 0,385060906 \\ 0,013412077 & 0,17115843\end{array}$

$-0,112046548$

0,276836973

0,252575901

$-0,023191068$

0,105965159

$-0,004550533$

$-0,083349899$

0,256852462

0,350814664

0,030743393

9,96E-05

$-0,027624145$

0,20057353

0,113546402
0,189678365

0,260361992

0,204056737

$-0,015904752$

0,186592263

0,265938606

$-0,08267295$

0,284714887

0,199688951

0,321599916

$-0,014462525$

0,053026921

0,121614284

0,326660578 


\begin{tabular}{|c|c|c|c|c|}
\hline ine_Hippurate & Urine_Methylnicotinamide & Serum_Formate & Serum_Phenylalanine & Serum_Histidine \\
\hline 0,004850229 & 0,017643005 & $-0,080681182$ & 0,096697004 & $-0,199709988$ \\
\hline$-0,071957594$ & 0,314723638 & $-0,289883954$ & $-0,179007981$ & $-0,306507247$ \\
\hline$-0,084104306$ & 0,212392292 & 0,033412082 & $-0,315524503$ & $-0,264595917$ \\
\hline 0,11725234 & $-0,174366706$ & $-0,003902729$ & $-0,222588104$ & $-0,489139031$ \\
\hline 0,337008332 & $-0,488040212$ & 0,061062769 & 0,133720885 & 0,272802296 \\
\hline$-0,056226244$ & 0,273605746 & 0,016803171 & $-0,247466011$ & $-0,33284466$ \\
\hline 0,017246382 & $-0,082846259$ & $-0,093498541$ & 0,445636578 & 0,120286624 \\
\hline 0,000871255 & 0,379140193 & $-0,234258405$ & 0,072308349 & $-0,113855423$ \\
\hline$-0,170823659$ & 0,463582259 & $-0,377537118$ & $-0,035220136$ & $-0,126884211$ \\
\hline$-0,380932817$ & 0,130713995 & 0,037126767 & $-0,082752062$ & 0,068219582 \\
\hline 0,124313238 & $-0,042522382$ & $-0,364728496$ & 0,12638587 & $-0,047093906$ \\
\hline$-0,130495068$ & 0,065651718 & 0,042896317 & $-0,028414503$ & $-0,11236972$ \\
\hline 0,130425716 & $-0,500549542$ & 0,079620305 & 0,060444525 & 0,170538984 \\
\hline 1 & $-0,270437565$ & $-0,201168662$ & 0,280947108 & 0,156662999 \\
\hline$-0,270437565$ & 1 & $-0,347108223$ & $-0,195701998$ & 0,024343339 \\
\hline$-0,201168662$ & $-0,347108223$ & 1 & 0,157703015 & 0,126945105 \\
\hline 0,280947108 & $-0,195701998$ & 0,157703015 & 1 & 0,534152011 \\
\hline 0,156662999 & 0,024343339 & 0,126945105 & 0,534152011 & . \\
\hline 0,06476738 & $-0,042324495$ & 0,232641447 & 0,721805934 & 0,217698082 \\
\hline$-0,117892999$ & $-0,082132934$ & 0,180249829 & 0,071222601 & 0,010328893 \\
\hline$-0,008813689$ & $-0,34137778$ & 0,243388081 & 0,030501703 & $-0,004321937$ \\
\hline 0,135663743 & 0,024790405 & 0,031873459 & 0,217499366 & 0,33771525 \\
\hline$-0,164170721$ & $-0,071661489$ & 0,077512571 & 0,083575879 & 0,299957433 \\
\hline 0,223796314 & $-0,46259052$ & $-0,158938342$ & 0,211286884 & 0,142686728 \\
\hline$-0,333750647$ & 0,562797309 & 0,069337459 & $-0,079118317$ & 0,236282557 \\
\hline$-0,350877021$ & 0,157742628 & 0,22744548 & 0,120221212 & 0,207076648 \\
\hline 0,079215838 & 0,027224865 & $-0,203162227$ & 0,320314076 & 0,472061881 \\
\hline 0,007534547 & $-0,266811708$ & 0,354592442 & 0,462544237 & 0,457637587 \\
\hline 0,129512636 & $-0,262540126$ & 0,243853046 & 0,442535323 & 0,753444774 \\
\hline 0,163238622 & $-0,156982899$ & 0,030394688 & 0,302376854 & 0,310166122 \\
\hline$-0,188541057$ & $-0,106719198$ & $-0,054783754$ & 0,007711036 & $-0,124809817$ \\
\hline$-0,092665832$ & 0,282432965 & 0,036139415 & $-0,061041012$ & 0,098177838 \\
\hline 0,152667702 & $-0,210018021$ & 0,424820754 & 0,116425682 & 0,026328814 \\
\hline 0,15778129 & $-0,212641055$ & $-0,143810129$ & 0,426838835 & 0,312068748 \\
\hline$-0,16907377$ & $-0,050425752$ & 0,066844416 & 0,085968627 & 0,328130657 \\
\hline$-0,007435881$ & 0,071985198 & 0,157422324 & 0,050748724 & 0,220031514 \\
\hline$-0,062393892$ & 0,20232733 & $-0,102234625$ & 0,562668124 & 0,557120945 \\
\hline 0,096069031 & 0,003334698 & $-0,006274917$ & 0,510563834 & 0,254085832 \\
\hline 0,040840376 & $-0,004303146$ & 0,035911459 & 0,68793429 & 0,490741448 \\
\hline 0,000211022 & 0,00565314 & $-0,109900606$ & 0,022505407 & $-0,243319288$ \\
\hline$-0,116395785$ & $-0,052267084$ & 0,044654536 & $-0,058616582$ & $-0,017766841$ \\
\hline$-0,141381634$ & 0,320574615 & $-0,044275687$ & $-0,063786863$ & 0,115134213 \\
\hline 0,155152717 & $-0,200365802$ & 0,014499588 & 0,277899074 & $-0,076567845$ \\
\hline 0,0675973 & 0,064631575 & $-0,151829591$ & 0,06421567 & $-0,170719261$ \\
\hline$-0,146397356$ & 0,061648957 & $-0,159848698$ & $-0,130332184$ & $-0,194674824$ \\
\hline 0,120897682 & 0,08696953 & $-0,158893665$ & $-0,100916079$ & 0,011261037 \\
\hline$-0,239004466$ & 0,34108553 & $-0,051313047$ & $-0,29297488$ & $-0,036361518$ \\
\hline$-0,147194842$ & 0,089305136 & 0,145527134 & 0,083180785 & 0,267692218 \\
\hline 0,219992422 & $-0,052675837$ & 0,1284985 & 0,187042929 & 0,204598984 \\
\hline
\end{tabular}



$-0,006143035$
$-0,005525937$
0,134166635
$-0,053374124$
$-0,02353294$
0,24674875
0,154507795
0,016719867
0,025858212
$-0,004011023$
0,277618762
0,036432337
$-0,300513707$
$-0,065500439$

$\begin{array}{rr}-0,0157731 & 0,002774951 \\ -0,080797294 & -0,144727419 \\ -0,188684488 & -0,206636088 \\ 0,062530983 & -0,149159168 \\ -0,243555916 & -0,12133964 \\ -0,067665085 & -0,16263574 \\ -0,154676748 & 0,130555476 \\ -0,084760795 & -0,140558169 \\ -0,14853928 & -0,088571176 \\ -0,148804951 & -0,032401486 \\ -0,097560984 & -0,206913206 \\ -0,086536657 & -0,136071787 \\ 0,023161148 & -0,298773119 \\ -0,044946986 & -0,033185691\end{array}$

0,059763115

0,206704474

0,234625101

$-0,042266516$

0,0317719

0,29100988

0,306058759

0,148842949

0,148330213

0,030085358

0,437080947

$-0,029735789$

0,113070015

0,124643686
0,158831427

0,009926779

0,03931064

0,17279445

0,05191235

0,194519564

0,3264403

0,03473051

0,018008454

0,149961904

0,039347967

$-0,105701487$

$-0,281355398$

0,036645631 
Serum_Tyrosine Serum_Glucose Serum_Mannose Serum_Proline Serum_Lactate Serum_Creatinine

\begin{tabular}{|c|c|c|c|c|c|}
\hline 0,133774594 & $-0,105390893$ & $-0,033444278$ & 0,020228743 & $-0,069959393$ & $-0,232607673$ \\
\hline$-0,126314407$ & 0,133787329 & 0,139990571 & $-0,010500762$ & 0,084156221 & $-0,459942583$ \\
\hline ,141751124 & $-0,110286514$ & $-0,056498107$ & $-0,074095401$ & $-0,106496254$ & $-0,628370652$ \\
\hline$-0,086525546$ & 0,001752475 & 0,109865261 & $-0,141520349$ & $-0,287596602$ & $-0,360298057$ \\
\hline$-0,155299711$ & $-0,015095424$ & 0,106196011 & 0,151655676 & $-0,113947031$ & 0,493877187 \\
\hline$-0,045150807$ & $-0,019517961$ & $-0,02874858$ & $-0,299321473$ & $-0,328705436$ & $-0,664553674$ \\
\hline 0,173062836 & 0,114996962 & 0,044818358 & 0,188971881 & 0,041040991 & 0,286293945 \\
\hline 0,082644429 & 0,18860556 & $-0,002104631$ & 0,084578183 & $-0,203620276$ & $-0,565493823$ \\
\hline 0,031696533 & $-0,088179831$ & $-0,14141067$ & $-0,162826537$ & 0,049013338 & 9392 \\
\hline$-0,080407668$ & 0,03227071 & $-0,087717393$ & $-0,174706167$ & $-0,053807003$ & 0,056278437 \\
\hline$-0,076536557$ & 0,326565339 & 0,331703205 & 0,241458838 & 0,359845868 & 0,121599585 \\
\hline$-0,004937939$ & 0,379385242 & 0,253710793 & 0,07577202 & 0,056944387 & $-0,209789591$ \\
\hline$-0,202702022$ & 0,064429674 & 0,171771538 & 0,330350795 & $-0,050545366$ & 0,430562893 \\
\hline 0,06476738 & $-0,117892999$ & $-0,008813689$ & 0,135663743 & $-0,164170721$ & 0,223796314 \\
\hline$-0,042324495$ & $-0,082132934$ & $-0,34137778$ & 0,024790405 & $-0,071661489$ & $-0,46259052$ \\
\hline 0,232641447 & 0,180249829 & 0,243388081 & 0,031873459 & 0,077512571 & $-0,158938342$ \\
\hline 0,721805934 & 0,071222601 & 0,030501703 & 0,217499366 & 0,083575879 & 0,211286884 \\
\hline 0,217698082 & 0,010328893 & $-0,004321937$ & 0,33771525 & 0,299957433 & 0,142686728 \\
\hline 1 & $-0,078022678$ & $-0,249$ & $-0,083$ & $-0,09590082$ & 5791 \\
\hline$-0,078022678$ & 1 & 0,743212031 & 0,315512699 & 0,1459828 & 21021 \\
\hline$-0,249567242$ & 0,743212031 & 1 & 0,147851279 & 0,161739493 & 0,149476727 \\
\hline$-0,083702753$ & 0,315512699 & 0,147 & 1 & 0,160640197 & 129 \\
\hline 90082 & 0,1459828 & 0,161 & 0,160 & 1 & 0,051288609 \\
\hline$-0,103136791$ & $-0,023121021$ & 0,149 & 0,014 & 0,051288609 & \\
\hline 0,00341114 & $-0,124008071$ & $-0,2141$ & $-0,111266458$ & $-0,215158232$ & $-0,28371289$ \\
\hline 0,255354393 & $-0,011452998$ & $-0,102003779$ & 0,180443933 & $-0,156803$ & $-0,008902294$ \\
\hline 0,149620897 & $-0,138244121$ & $-0,207$ & 0,006 & 0,176896984 & 5586 \\
\hline 0,355227484 & $-0,121028832$ & $-0,0491$ & 0,144 & 0,003781113 & 0,180283618 \\
\hline 0,26489166 & $-0,034804118$ & 0,01 & 0,26 & 0,204008229 & 3777 \\
\hline 0,210425071 & 0,3863793 & 0,2540 & 0,39 & 0,455305867 & 0346 \\
\hline$-0,019115545$ & 0,285833664 & 0,283095534 & $-0,075359713$ & 0,695230456 & 0,054791766 \\
\hline$-0,200760333$ & 0,213412711 & 0,110201989 & 0,825880005 & 0,078095672 & $-0,173801047$ \\
\hline 0,037135935 & 0,215100483 & 0,2021 & 0,2707856 & $-0,039084478$ & 0,025510533 \\
\hline 0,248349627 & 0,172460073 & 0,1001 & 0,030317118 & 0,248892316 & 0471 \\
\hline$-0,094465678$ & 0,118456243 & 0,1332 & 0,172497291 & 0,996813284 & 0,04 \\
\hline$-0,161$ & 0,22614139 & 0,17 & $0,8 \varepsilon$ & 0,11504244 & 7955193 \\
\hline 0,539781021 & 0,114014778 & $-0,028711865$ & 0,194583372 & 0,31992881 & 0,018563298 \\
\hline 0,415351531 & 0,077880872 & 0,104767391 & 0,060251162 & $-0,015781102$ & 0,066133181 \\
\hline 0,525677788 & 0,157850896 & 0,122515282 & 0,178988711 & 0,219627742 & 0,168695784 \\
\hline 0,081586059 & $-0,146602632$ & $-0,170430167$ & $-0,099236721$ & $-0,162512517$ & 0,032128825 \\
\hline$-0,100429834$ & 0,303735619 & 0,284681591 & 0,006461353 & 0,165267074 & $-0,012955039$ \\
\hline 0,028069542 & $-0,164109892$ & $-0,312458086$ & $-0,045867894$ & 0,052091625 & $-0,323058853$ \\
\hline 0,151228701 & 0,056674513 & 0,216766423 & $-0,050384078$ & 0,041912693 & 0,487456115 \\
\hline 0,048879471 & $-0,008917997$ & $-0,000926509$ & $-0,041434017$ & $-0,156122676$ & 0,046063053 \\
\hline 0,004540675 & $-0,265816649$ & $-0,240017738$ & $-0,205213051$ & 0,011741724 & 0,032421042 \\
\hline$-0,21452273$ & 0,269235889 & 0,226409645 & 0,496139795 & $-0,037882248$ & $-0,222531051$ \\
\hline$-0,050132325$ & $-0,323741307$ & $-0,374503036$ & $-0,147851994$ & 0,005832525 & $-0,372333886$ \\
\hline 0,015118288 & 0,0917393 & 0,260617795 & $-0,101089282$ & 0,193739739 & $-0,046794992$ \\
\hline$-0,018021311$ & 0,154974463 & 0,235914015 & 0,050309732 & 0,039785418 & $-0,00686417$ \\
\hline
\end{tabular}




$\begin{array}{rrrrrr}0,022268281 & 0,034228026 & -0,069790466 & 0,464309645 & 0,106496565 & 0,065753603 \\ 0,084121202 & 0,141594631 & 0,120019063 & 0,430790064 & 0,002731212 & 0,072862477 \\ 0,130117519 & 0,07242506 & 0,093176328 & 0,305271325 & 0,004645071 & 0,170840224 \\ -0,03147818 & -0,015146309 & -0,074329973 & 0,104320598 & 0,466833242 & -0,009326763 \\ -0,09064769 & 0,246688518 & 0,348755856 & 0,071210171 & 0,235269001 & 0,228601804 \\ 0,034699004 & 0,22548335 & 0,104579546 & 0,403993226 & 0,017007861 & 0,150351319 \\ 0,43473455 & -0,005796731 & -0,039736205 & 0,078922139 & 0,052800653 & -0,169257527 \\ 0,006153109 & 0,131027437 & 0,131535843 & 0,453309713 & 0,03210388 & 0,103059705 \\ 0,072205446 & 0,142970908 & 0,161849064 & 0,343737405 & -0,051876202 & 0,07757041 \\ -0,174449353 & 0,240603798 & 0,306572894 & 0,568183669 & 0,264931287 & 0,080402825 \\ 0,36742315 & -0,095321503 & -0,161111235 & -0,104064049 & -0,181996522 & 0,288044451 \\ -0,235871535 & 0,374623157 & 0,367110736 & -0,020970496 & 0,061155669 & 0,259575762 \\ 0,058336876 & 0,023851858 & 0,128319745 & -0,104536374 & -0,092189105 & 0,104045448 \\ -0,008635225 & 0,177276983 & 0,07612963 & 0,55090534 & 0,051647579 & 0,013042951\end{array}$


Serum_Creatine Serum_Glycerol Serum_Glycine Serum_Citrate Serum_Glutamine Serum_Glutamate

\begin{tabular}{|c|c|c|c|c|c|}
\hline 0,129911259 & $-0,246018745$ & $-0,285560055$ & 0,014799426 & $-0,399312114$ & 0,05679742 \\
\hline 0,035753292 & $-0,410661261$ & $-0,388180979$ & $-0,280128729$ & $-0,527392747$ & 0,142257482 \\
\hline 0,107348903 & $-0,387425318$ & $-0,593821148$ & $-0,19859416$ & $-0,473107561$ & $-0,023702619$ \\
\hline$-0,0760336$ & $-0,406872993$ & $-0,648952234$ & $-0,22026595$ & $-0,582770635$ & 0,041139218 \\
\hline$-0,106756523$ & 0,121938634 & 0,249065015 & 0,380746634 & 0,397134968 & $-0,09837466$ \\
\hline 0,273912533 & $-0,180589734$ & $-0,455202798$ & $-0,085433777$ & $-0,469713943$ & $-0,2507556$ \\
\hline 0,033859539 & $-0,088725717$ & 0,117192588 & 0,260483674 & 0,004675963 & 0,15236497 \\
\hline 0,251311388 & $-0,184235525$ & $-0,283864319$ & $-0,113947233$ & $-0,403101641$ & 0,1011640 \\
\hline 0,325236031 & $-0,234588938$ & $-0,065390765$ & $-0,049959348$ & $-0,406412204$ & 0,012226133 \\
\hline 0,422807655 & 0,282196179 & 0,077539503 & 0,224076138 & 0,113355863 & $-0,265752629$ \\
\hline$-0,304053937$ & $-0,351874904$ & $-0,026188925$ & $-0,195897807$ & $-0,218792254$ & 0,462163 \\
\hline 0,08329282 & $-0,014698328$ & $-0,206978499$ & $-0,179716738$ & $-0,201475073$ & 0,1655907 \\
\hline$-0,073988541$ & 0,283153844 & 0,157737093 & 0,358633982 & 0,346385351 & 0,0048963 \\
\hline$-0,333750647$ & $-0,350877021$ & 0,079215838 & 0,007534547 & 0,129512636 & 0,1632386 \\
\hline 0,562797309 & 0,157742628 & 0,027224865 & $-0,266811708$ & $-0,262540126$ & $-0,1569828$ \\
\hline 0,069337459 & 0,22744548 & $-0,203162227$ & 0,354592442 & 0,243853046 & 0,0303946 \\
\hline$-0,079118317$ & 0,120221212 & 0,320314076 & 0,462544237 & 0,442535323 & 0,30237685 \\
\hline 0,236282557 & 0,207076648 & 0,472061881 & 0,457637587 & 0,753444774 & 0,3101661 \\
\hline 0,00341114 & 0,255354393 & 0,149620897 & 0,355227484 & 0,26489166 & 0,21042507 \\
\hline$-0,124008071$ & $-0,011452998$ & $-0,138244121$ & $-0,121028832$ & $-0,034804118$ & 0,38637 \\
\hline$-0,214197753$ & $-0,102003779$ & $-0,207432908$ & $-0,049190776$ & 0,01190323 & 0,254083368 \\
\hline$-0,111266458$ & 0,180443933 & 0,006826818 & 0,144546541 & 0,263509641 & 0,3960104 \\
\hline$-0,215158232$ & $-0,156803$ & 0,176896984 & 0,003781113 & 0,204008229 & 0,455305867 \\
\hline$-0,28371289$ & $-0,008902294$ & 0,529415586 & 0,180283618 & 0,363723777 & $-0,0674203$ \\
\hline 1 & 0,417323108 & 0,032845747 & 0,121122154 & $-0,072880174$ & $-0,2953743$ \\
\hline 0,417323108 & 1 & 0,162123639 & 0,241189394 & 0,383085114 & $-0,0973841$ \\
\hline 0,032845747 & 0,162123639 & 1 & 0,340595074 & 0,62369689 & $-0,002882509$ \\
\hline 0,121122154 & 0,241189394 & 0,340595074 & 1 & 0,599310957 & $-0,205921884$ \\
\hline$-0,072880174$ & 0,383085114 & 0,62369689 & 0,599310957 & 1 & 0,1796354 \\
\hline$-0,29537435$ & $-0,097384198$ & $-0,002882509$ & $-0,205921884$ & 0,179635424 & \\
\hline$-0,283685722$ & $-0,221520887$ & $-0,032298886$ & $-0,104370014$ & $-0,159592096$ & 0,3764797 \\
\hline 0,024920817 & 0,353736462 & $-0,205740102$ & $-0,024563483$ & 0,054365859 & 0,1196956 \\
\hline 0,193477679 & 0,143616378 & $-0,28576547$ & 0,016017789 & $-0,089793053$ & 0,085561892 \\
\hline$-0,259527995$ & $-0,220746016$ & 0,480729382 & 0,127804803 & 0,340327354 & 0,3980397 \\
\hline$-0,198450843$ & $-0,138038984$ & 0,201120229 & 0,012178078 & 0,229754859 & 0,4454354 \\
\hline$-0,028941831$ & 0,29908706 & $-0,198120259$ & 0,152761779 & 0,176251946 & 0,158898161 \\
\hline 0,18946604 & 0,199691614 & 0,302977568 & 0,142095186 & 0,314737544 & 0,4911153 \\
\hline 0,24953171 & 0,062449602 & $-0,027369785$ & 0,005508805 & $-0,036431147$ & 0,2794781 \\
\hline 0,164914406 & 0,171325767 & 0,243263868 & 0,106857086 & 0,260920932 & 0,48450707 \\
\hline 0,004605724 & $-0,051511594$ & 0,115074222 & 0,162060815 & $-0,041836788$ & $-0,25317529$ \\
\hline$-0,103811219$ & $-0,139051809$ & $-0,078385112$ & $-0,124783072$ & $-0,105341582$ & 0,12616537 \\
\hline 0,066989189 & $-0,116682689$ & $-0,21900151$ & $-0,145805081$ & $-0,064413264$ & 0,1019807 \\
\hline$-0,283945171$ & 0,067930921 & 0,195978125 & 0,02392483 & 0,122045568 & $-0,039342416$ \\
\hline$-0,014563245$ & $-0,045331094$ & 0,167170747 & 0,02992743 & $-0,017797847$ & $-0,14335366$ \\
\hline$-0,179282645$ & $-0,0446772$ & 0,02428298 & 0,067218443 & $-0,056324376$ & $-0,2587256$ \\
\hline$-0,047161924$ & 0,011780055 & $-0,343939141$ & $-0,174751995$ & $-0,112624099$ & 0,197713127 \\
\hline 0,03905862 & $-0,06694854$ & $-0,287389474$ & $-0,273356234$ & $-0,16554592$ & 0,02386563 \\
\hline 0,053866955 & $-0,049564576$ & 0,177306915 & 0,015287307 & 0,127710863 & 0,0867841 \\
\hline$-0,106175717$ & $-0,08838253$ & 0,133589314 & 0,112549966 & 0,205020036 & 0,018122 \\
\hline
\end{tabular}




$\begin{array}{rrrrrr}-0,057233974 & 0,156494469 & 0,110186657 & 0,025664261 & 0,173522998 & 0,294149031 \\ -0,057682529 & 0,058290209 & -0,026247657 & 0,171776828 & 0,001399713 & 0,008898546 \\ -0,115447264 & -0,079972117 & 0,048496461 & 0,175440352 & 0,024540748 & 0,073169822 \\ 0,127976493 & -0,101624424 & 0,265862304 & 0,07675737 & 0,097530642 & 0,302826588 \\ -0,100818594 & 0,01461113 & 0,190618295 & -0,047910334 & 0,095248095 & 0,166520833 \\ -0,04027888 & 0,045694084 & 0,229487393 & 0,197084674 & 0,135604273 & 0,038007707 \\ -0,083943483 & 0,078196937 & 0,050477098 & 0,209807388 & 0,309611408 & 0,319788523 \\ -0,066137761 & 0,053177431 & 0,02376957 & 0,169483546 & 0,056920269 & 0,010838431 \\ -0,135556856 & 0,038605239 & -0,045676662 & 0,149474351 & 0,069678425 & -0,005823039 \\ -0,170705905 & 0,147750844 & 0,049695274 & 0,135822158 & 0,187212121 & 0,13808 \\ 0,062443638 & -0,09478963 & 0,191561935 & 0,14444333 & -0,043338404 & -0,069759629 \\ -0,185477201 & -0,136082578 & 0,218550146 & -0,282419681 & -0,022807982 & 0,11675271 \\ 0,144025009 & 0,088675992 & 0,036360462 & -0,072047109 & -0,311817893 & -0,129057615 \\ -0,071255182 & 0,162274584 & -0,038532234 & 0,223400129 & 0,087406861 & -0,028561032\end{array}$




\begin{tabular}{|c|c|c|c|c|}
\hline m_Pyruvate & Serum_A & Serc & & eru \\
\hline 0,030925488 & $-0,101339739$ & 0,23028259 & $-0,122399228$ & $-0,076254979$ \\
\hline 0,26420332 & 0,025067191 & $-0,099026049$ & $-0,11181882$ & 0,064147553 \\
\hline$-0,031413305$ & 0,029711112 & 0,076300721 & $-0,356770594$ & $-0,122125068$ \\
\hline 0,031949772 & $-0,133774758$ & 0,2133756 & $-0,280817126$ & $-0,328913164$ \\
\hline$-0,024906516$ & $-0,057109825$ & 0,088047014 & 0,263347471 & $-0,120953857$ \\
\hline 0,030302395 & $-0,138756427$ & $-0,09109013$ & $-0,1516697$ & $-0,346396355$ \\
\hline 0,155136676 & $-0,059204708$ & 0,044657898 & 0,304575376 & 0,036998636 \\
\hline 0,039333522 & 0,052706914 & $-0,068182943$ & $-0,048068192$ & $-0,211773198$ \\
\hline 0,241690582 & $-0,163498333$ & $-0,31845781$ & 0,036558416 & 0,043452027 \\
\hline 0,010285122 & $-0,104126628$ & 0,037404194 & $-0,181630351$ & $-0,066984349$ \\
\hline 0,488348024 & 0,063506957 & $-0,059049279$ & 0,384172453 & 0,344894667 \\
\hline 0,086302756 & $-0,019856265$ & 0,230344129 & $-0,019131715$ & 0,038027721 \\
\hline 0,016704383 & 0,175550068 & 0,241421577 & 0,138275682 & $-0,05850652$ \\
\hline$-0,188541057$ & $-0,092665832$ & 0,152667702 & 0,15778129 & $-0,16907377$ \\
\hline$-0,106719198$ & 0,282432965 & $-0,210018021$ & $-0,212641055$ & $-0,050425752$ \\
\hline$-0,054783754$ & 0,036139415 & 0,424820754 & $-0,143810129$ & 0,066844416 \\
\hline 0,007711036 & $-0,061041012$ & 0,116425682 & 0,426838835 & 0,085968627 \\
\hline$-0,124809817$ & 0,098177838 & 0,026328814 & 0,312068748 & 0,328130657 \\
\hline$-0,019115545$ & $-0,200760333$ & 0,037135935 & 0,248349627 & $-0,094465678$ \\
\hline 0,285833664 & 0,213412711 & 0,215100483 & 0,172460073 & 0,118456243 \\
\hline 0,283095534 & 0,110201989 & 0,202122419 & 0,100167161 & 0,133272948 \\
\hline$-0,075359713$ & 0,825880005 & 0,2707856 & 0,030317118 & 0,172497291 \\
\hline 0,695230456 & 0,078095672 & $-0,039084478$ & 0,248892316 & 0,996813284 \\
\hline 0,054791766 & $-0,173801047$ & 0,025510533 & 0,360390471 & 0,048041365 \\
\hline$-0,283685722$ & 0,024920817 & 0,193477679 & $-0,259527995$ & $-0,198450843$ \\
\hline$-0,221520887$ & 0,353736462 & 0,143616378 & $-0,220746016$ & $-0,138038984$ \\
\hline$-0,032298886$ & $-0,205740102$ & $-0,28576547$ & 0,480729382 & 0,201120229 \\
\hline$-0,104370014$ & $-0,024563483$ & 0,016017789 & 0,127804803 & 0,012178078 \\
\hline$-0,159592096$ & 0,054365859 & $-0,089793053$ & 0,340327354 & 0,229754859 \\
\hline 0,376479711 & 0,119695615 & 0,085561892 & 0,398039745 & 0,445435497 \\
\hline 1 & $-0,077691877$ & $-0,048822758$ & 0,375990718 & 0,659482336 \\
\hline$-0,077691877$ & 1 & 0,28297451 & $-0,331025682$ & 0,086320479 \\
\hline$-0,048822758$ & 0,28297451 & 1 & $-0,242798796$ & $-0,062439871$ \\
\hline 0,375990718 & $-0,331025682$ & $-0,242798796$ & 1 & 0,24846584 \\
\hline 0,659482336 & 0,086320479 & $-0,062439871$ & 0,24846584 & 1 \\
\hline$-0,075824553$ & 0,91529698 & 0,273231006 & $-0,173368477$ & 0,126123376 \\
\hline 0,220758207 & 0,006870753 & $-0,039290293$ & 0,378875761 & 0,328805631 \\
\hline 0,043434039 & $-0,131254379$ & 0,300147381 & 0,27172414 & $-0,018612096$ \\
\hline 0,183265168 & $-0,06673188$ & 0,1881505 & 0,484748393 & 0,221236546 \\
\hline$-0,071545949$ & $-0,134712153$ & $-0,114331092$ & 0,021120841 & $-0,154178747$ \\
\hline 0,253922948 & $-0,046013114$ & $-0,047832144$ & 0,154734353 & 0,135505244 \\
\hline$-0,056965386$ & $-0,065044306$ & $-0,136308635$ & $-0,000243406$ & 0,080759562 \\
\hline 0,058041645 & $-0,052308253$ & 0,011470835 & 0,058987167 & 0,02945394 \\
\hline$-0,076527589$ & $-0,049227233$ & $-0,048469451$ & 0,048085924 & $-0,154017355$ \\
\hline 0,007575938 & $-0,124715672$ & $-0,35486166$ & $-0,044201904$ & 0,013846448 \\
\hline$-0,032865424$ & 0,461388352 & 0,111164295 & $-0,031854584$ & $-0,036329188$ \\
\hline$-0,101219136$ & $-0,028643605$ & $-0,296342849$ & $-0,173385685$ & 0,036046864 \\
\hline 0,049738545 & $-0,108627519$ & $-0,099149823$ & 0,092580203 & 0,188112425 \\
\hline$-0,008332177$ & 0,037707864 & 0,149977303 & 0,064265425 & 0,024805773 \\
\hline
\end{tabular}




$\begin{array}{rrrrr}0,031173314 & 0,305212776 & -0,05390619 & 0,200230075 & 0,123283855 \\ 0,094766303 & 0,298861616 & -0,022146559 & 0,144631658 & -0,002834118 \\ 0,053310429 & 0,07247113 & -0,09382496 & 0,186614872 & 0,003107374 \\ 0,278902708 & -0,084066141 & -0,137097274 & 0,160767239 & 0,482432671 \\ 0,19026846 & -0,112039173 & -0,191896332 & 0,211067442 & 0,243254125 \\ 0,020321259 & 0,232735769 & -0,146273715 & 0,213990384 & 0,020811741 \\ -0,101782019 & -0,068783487 & -0,018512811 & 0,11264509 & 0,057780369 \\ 0,09716391 & 0,315813296 & -0,033044372 & 0,189270164 & 0,027174497 \\ -0,026106328 & 0,210124259 & -0,065834954 & 0,091365598 & -0,058707951 \\ 0,155104832 & 0,46483366 & -0,046562687 & 0,083963236 & 0,272247268 \\ -0,049034708 & -0,285391008 & -0,012270893 & 0,157753452 & -0,185445736 \\ 0,185865807 & -0,112233525 & -0,179728566 & 0,349430634 & 0,060902552 \\ 0,161272839 & -0,102992507 & -0,127662777 & 0,086717741 & -0,092302173 \\ 0,103050381 & 0,498381683 & 0,032575404 & 0,081306118 & 0,045582783\end{array}$


Serum_3.hydroxybutyrate Serum_Valine Serum_Isoleucine Serum_Leucine Sputum_propionato

\begin{tabular}{|c|c|c|c|c|}
\hline$-0,08546291$ & 0,125195209 & 0,473472805 & 0,240260243 & 0,167362084 \\
\hline$-0,035825879$ & 0,126099239 & 0,136379404 & 0,019352954 & 0,027962543 \\
\hline 0,035418461 & $-0,163099445$ & $-0,013094146$ & $-0,226767042$ & $-0,008591784$ \\
\hline$-0,136353932$ & $-0,216943005$ & 0,125233537 & $-0,159059393$ & $-0,034984725$ \\
\hline 0,114560585 & $-0,104932403$ & $-0,052656047$ & 0,011708631 & $-0,014452614$ \\
\hline$-0,102447163$ & $-0,26009338$ & $-0,056026635$ & $-0,257221216$ & 0,043511123 \\
\hline 0,01526984 & 0,29608467 & 0,393648215 & 0,417093601 & 0,338270206 \\
\hline 0,009881483 & 0,157454047 & 0,190280017 & 0,087916751 & 0,120642451 \\
\hline$-0,220427441$ & 0,321988041 & 0,265813678 & 0,173626046 & 0,36990193 \\
\hline$-0,125840085$ & 0,010002686 & 0,019084586 & 0,018113628 & 0,014032137 \\
\hline 0,04859208 & 0,381343268 & 0,318975004 & 0,375793779 & 0,15647108 \\
\hline$-0,026830618$ & 0,137429753 & 0,31043461 & 0,235301194 & 0,155432684 \\
\hline 0,305879827 & $-0,109689002$ & $-0,072841551$ & 0,019476627 & 0,020912023 \\
\hline$-0,007435881$ & $-0,062393892$ & 0,096069031 & 0,040840376 & 0,000211022 \\
\hline 0,071985198 & 0,20232733 & 0,003334698 & $-0,004303146$ & 0,00565314 \\
\hline 0,157422324 & $-0,102234625$ & $-0,006274917$ & 0,035911459 & $-0,109900606$ \\
\hline 0,050748724 & 0,562668124 & 0,510563834 & 0,68793429 & 0,022505407 \\
\hline 0,220031514 & 0,557120945 & 0,254085832 & 0,490741448 & $-0,243319288$ \\
\hline$-0,161105951$ & 0,539781021 & 0,415351531 & 0,525677788 & 0,081586059 \\
\hline 0,22614139 & 0,114014778 & 0,077880872 & 0,157850896 & $-0,146602632$ \\
\hline 0,171550051 & $-0,028711865$ & 0,104767391 & 0,122515282 & $-0,170430167$ \\
\hline 0,883650234 & 0,194583372 & 0,060251162 & 0,178988711 & $-0,099236721$ \\
\hline 0,11504244 & 0,31992881 & $-0,015781102$ & 0,219627742 & $-0,162512517$ \\
\hline$-0,147955193$ & 0,018563298 & 0,066133181 & 0,168695784 & 0,032128825 \\
\hline$-0,028941831$ & 0,18946604 & 0,24953171 & 0,164914406 & 0,004605724 \\
\hline 0,29908706 & 0,199691614 & 0,062449602 & 0,171325767 & $-0,051511594$ \\
\hline$-0,198120259$ & 0,302977568 & $-0,027369785$ & 0,243263868 & 0,115074222 \\
\hline 0,152761779 & 0,142095186 & 0,005508805 & 0,106857086 & 0,162060815 \\
\hline 0,176251946 & 0,314737544 & $-0,036431147$ & 0,260920932 & $-0,041836788$ \\
\hline 0,158898161 & 0,491115358 & 0,279478169 & 0,484507073 & $-0,25317529$ \\
\hline$-0,075824553$ & 0,220758207 & 0,043434039 & 0,183265168 & $-0,071545949$ \\
\hline 0,91529698 & 0,006870753 & $-0,131254379$ & $-0,06673188$ & $-0,134712153$ \\
\hline 0,273231006 & $-0,039290293$ & 0,300147381 & 0,1881505 & $-0,114331092$ \\
\hline$-0,173368477$ & 0,378875761 & 0,27172414 & 0,484748393 & 0,021120841 \\
\hline 0,126123376 & 0,328805631 & $-0,018612096$ & 0,221236546 & $-0,154178747$ \\
\hline 1 & 0,000827311 & $-0,062744175$ & $-0,002065709$ & $-0,117098281$ \\
\hline 0,000827311 & 1 & 0,649913358 & 0,846846662 & $-0,055427689$ \\
\hline$-0,062744175$ & 0,649913358 & 1 & 0,877474357 & $-0,016010016$ \\
\hline$-0,002065709$ & 0,846846662 & 0,877474357 & 1 & $-0,060957119$ \\
\hline$-0,117098281$ & $-0,055427689$ & $-0,016010016$ & $-0,060957119$ & 1 \\
\hline$-0,044556758$ & 0,151776664 & 0,053436016 & 0,058044855 & $-0,179656091$ \\
\hline$-0,015620043$ & $-0,025758673$ & 0,043771483 & $-0,040541454$ & $-0,099112834$ \\
\hline$-0,15512297$ & 0,14891566 & 0,161124924 & 0,201531642 & $-0,030561542$ \\
\hline$-0,096267164$ & 0,033934269 & 0,008315749 & 0,02175215 & 0,839484497 \\
\hline$-0,127919828$ & $-0,056130211$ & $-0,089900717$ & $-0,135315591$ & 0,201301583 \\
\hline 0,492715731 & 0,001258051 & 0,051540119 & $-0,002254909$ & $-0,039372284$ \\
\hline$-0,029902209$ & $-0,058092113$ & 0,00384704 & $-0,129279844$ & $-0,104933532$ \\
\hline$-0,092375425$ & 0,275647006 & 0,116608852 & 0,205526286 & $-0,182704421$ \\
\hline 0,015412525 & 0,00387549 & $-0,053290215$ & 0,019224391 & $-0,131728594$ \\
\hline
\end{tabular}




$\begin{array}{rrrrr}0,382006068 & 0,122696976 & 0,02044656 & 0,131614212 & -0,167139546 \\ 0,388287264 & 0,23277613 & 0,272695025 & 0,241923598 & 0,062328018 \\ 0,168186035 & 0,292209982 & 0,323740287 & 0,277763178 & 0,049322578 \\ -0,046948899 & 0,292261128 & 0,079514488 & 0,158033169 & -0,026434195 \\ 0,034552917 & 0,129388535 & 0,178663946 & 0,192645548 & -0,084280498 \\ 0,362296788 & 0,15646795 & 0,087900779 & 0,150161321 & 0,071571902 \\ 0,097976764 & 0,237189815 & 0,094780651 & 0,174925966 & -0,117538661 \\ 0,412606817 & 0,162899493 & 0,184100039 & 0,182189647 & 0,021632867 \\ 0,294301535 & 0,160425233 & 0,183743512 & 0,147819485 & -0,019225902 \\ 0,626795209 & 0,058651673 & 0,013470001 & 0,064608478 & -0,107720262 \\ -0,26310057 & 0,314156736 & 0,383034149 & 0,343715361 & 0,230778508 \\ -0,042440463 & -0,169739251 & 0,014373682 & 0,053844953 & -0,065513935 \\ -0,110964861 & 0,163769191 & 0,364536382 & 0,300358011 & 0,351009781 \\ 0,588351874 & 0,113049211 & 0,045700111 & 0,076148678 & 0,075798099\end{array}$


Sputum_lactate

$-0,026477288$

0,227942625

0,084272811

0,107447311

0,080370245

0,064419381

0,100077226

0,11018073

0,185758495

$-0,012908524$

0,311279752

0,298902906

0,004640738

$-0,116395785$

$-0,052267084$

0,044654536

$-0,058616582$

$-0,017766841$

$-0,100429834$

0,303735619

0,284681591

0,006461353

0,165267074

$-0,012955039$

$-0,103811219$

$-0,139051809$

$-0,078385112$

$-0,124783072$

$-0,105341582$

0,126165378

0,253922948

$-0,046013114$

$-0,047832144$

0,154734353

0,135505244

$-0,044556758$

0,151776664

0,053436016

0,058044855

$-0,179656091$

$-0,213723909$

0,147208943

$-0,219644673$

$-0,018750179$

0,242031003

$-0,166783462$

0,352557762

0,109054388
Sputum_acetoin

0,144526198

0,079956151

0,301920419

0,013385132

$-0,289264362$

0,192454658

$-0,033046436$

0,153170994

0,04315247

0,112212044

$-0,184987461$

0,026368864

$-0,38209428$

$-0,141381634$

0,320574615

$-0,044275687$

$-0,063786863$

0,115134213

0,028069542

$-0,164109892$

$-0,312458086$

$-0,045867894$

0,052091625

$-0,323058853$

0,066989189

$-0,116682689$

$-0,21900151$

$-0,145805081$

$-0,064413264$

0,101980796

$-0,056965386$

$-0,065044306$

$-0,136308635$

$-0,000243406$

0,080759562

$-0,015620043$

$-0,025758673$

0,043771483

$-0,040541454$

$-0,099112834$

$-0,213723909$

$-0,341425992$

$-0,270630927$

0,113286592

0,055305245

0,802285075

$-0,213606424$

$-0,198029454$
Sputum_alanine

$-0,096985078$

$-0,145957388$

$-0,450299595$

$-0,156984526$

0,103866952

$-0,477205255$

0,08839145

$-0,339633089$

$-0,184874092$

$-0,140362239$

0,144693997

0,076662417

0,054594102

0,155152717

$-0,200365802$

0,014499588

0,277899074

$-0,076567845$

0,151228701

0,056674513

0,216766423

$-0,050384078$

0,041912693

0,487456115

$-0,283945171$

0,067930921

0,195978125

0,02392483

0,122045568

$-0,039342416$

0,058041645

$-0,052308253$

0,011470835

0,058987167

0,02945394

$-0,15512297$

0,14891566

0,161124924

0,201531642

$-0,030561542$

0,147208943

$-0,341425992$

0,154663766

$-0,00734063$

$-0,063267876$

$-0,295380083$

0,144351202

0,367080264
Sputum_acetate Sputum_acetone

0,004573839

0,016916734

$-0,087685936$

$-0,074788835$

$-0,060845305$

$-0,066760099$

0,183880338

0,026068883

0,280706854

$-0,102507657$

0,246042439

0,12726099

$-0,019368477$

0,0675973

0,064631575

$-0,151829591$

0,06421567

$-0,170719261$

0,048879471

$-0,008917997$

$-0,000926509$

$-0,041434017$

$-0,156122676$

0,046063053

$-0,014563245$

$-0,045331094$

0,167170747

0,02992743

$-0,017797847$

$-0,143353664$

$-0,076527589$

$-0,049227233$

$-0,048469451$

0,048085924

$-0,154017355$

$-0,096267164$

0,033934269

0,008315749

0,02175215

0,839484497

$-0,219644673$

$-0,270630927$

0,154663766

0,07367022

$-0,003648837$

$-0,282188727$

0,132389838

0,223502687
$-0,105971794$

$-0,013892743$

0,024358254

$-0,121344843$

$-0,235099132$

$-0,042495369$

$-0,15827108$

$-0,153722679$

0,021242668

0,039326595

$-0,039426805$

$-0,112740222$

$-0,270203663$

$-0,146397356$

0,061648957

$-0,159848698$

$-0,130332184$

$-0,194674824$

0,004540675

$-0,265816649$

$-0,240017738$

$-0,205213051$

0,011741724

0,032421042

$-0,179282645$

$-0,0446772$

0,02428298

0,067218443

$-0,056324376$

$-0,258725699$

0,007575938

$-0,124715672$

$-0,35486166$

$-0,044201904$

0,013846448

$-0,127919828$

$-0,056130211$

$-0,089900717$

$-0,135315591$

0,201301583

$-0,018750179$

0,113286592

$-0,00734063$

0,07367022

$-0,262240328$

0,159768485

$-0,091480161$

$-0,26858178$ 


$\begin{array}{rrrrr}-0,165036748 & 0,052476097 & -0,224732014 & -0,202722882 & -0,039683441 \\ 0,24196318 & -0,240745192 & 0,244744282 & 0,091840197 & -0,132245799 \\ 0,207205605 & -0,215874536 & 0,297139994 & 0,031182241 & -0,148570522 \\ -0,068184804 & -0,052021379 & -0,050767535 & -0,089403436 & -0,125451236 \\ 0,110924469 & -0,147383526 & 0,080702754 & -0,106365038 & -0,110068083 \\ 0,118981056 & -0,246352385 & 0,111128956 & 0,086001368 & -0,117983116 \\ -0,110081064 & 0,195726739 & -0,117876882 & -0,189960888 & -0,047440352 \\ 0,252000041 & -0,230588196 & 0,216155242 & 0,060806151 & -0,122073581 \\ 0,323759138 & -0,207047245 & 0,333787419 & 0,027439333 & -0,114399435 \\ 0,056314051 & -0,141746713 & -0,012723556 & -0,089265558 & -0,089254255 \\ -0,078872948 & -0,09210502 & 0,206489573 & 0,151553396 & -0,136086358 \\ 0,006041944 & -0,037553268 & -0,006139023 & -0,017655662 & -0,053946195 \\ 0,048326331 & -0,268111893 & 0,082058778 & 0,336293961 & 0,025573828 \\ 0,140910837 & -0,237128472 & 0,115975475 & 0,13809019 & -0,115744723\end{array}$




\begin{tabular}{|c|c|c|c|c|}
\hline 0,106467691 & 0,103370334 & $-0,164989698$ & $-0,193479667$ & $-0,033868192$ \\
\hline 0,233378905 & 0,087239348 & $-0,02432712$ & $-0,083288917$ & $-0,062490945$ \\
\hline 0,085878999 & 0,341340572 & $-0,00250079$ & $-0,078782161$ & $-0,034076474$ \\
\hline 0,202811061 & 0,075963831 & $-0,136944042$ & $-0,030762078$ & $-0,133300712$ \\
\hline 0,131051924 & $-0,341776333$ & $-0,144040725$ & 0,150854376 & 0,04645023 \\
\hline 0,114743135 & 0,170352898 & $-0,126924443$ & $-0,027260358$ & $-0,132179569$ \\
\hline 0,035742505 & $-0,205210828$ & $-0,143478116$ & $-0,11271591$ & 0,007618277 \\
\hline 0,333838459 & 0,007407079 & $-0,190707737$ & $-0,083934341$ & $-0,026280243$ \\
\hline 0,105692828 & 0,14029394 & 0,112299894 & $-0,215612998$ & $-0,145423451$ \\
\hline$-0,157105542$ & $-1,33 E-05$ & $-0,070883149$ & $-0,029343191$ & $-0,173703762$ \\
\hline 0,327785622 & $-0,203512441$ & 0,145026273 & 0,009552834 & $-0,012030201$ \\
\hline 0,421838569 & $-0,062881409$ & 0,023986632 & 0,047877861 & $-0,112046548$ \\
\hline 0,205557188 & $-0,423547566$ & $-0,162924058$ & 0,129312241 & 0,189678365 \\
\hline 0,120897682 & $-0,239004466$ & $-0,147194842$ & 0,219992422 & $-0,006143035$ \\
\hline 0,08696953 & 0,34108553 & 0,089305136 & $-0,052675837$ & $-0,0157731$ \\
\hline$-0,158893665$ & $-0,051313047$ & 0,145527134 & 0,1284985 & 0,002774951 \\
\hline$-0,100916079$ & $-0,29297488$ & 0,083180785 & 0,187042929 & 0,059763115 \\
\hline 0,011261037 & $-0,036361518$ & 0,267692218 & 0,204598984 & 0,158831427 \\
\hline$-0,21452273$ & $-0,050132325$ & 0,015118288 & $-0,018021311$ & 0,022268281 \\
\hline 0,269235889 & $-0,323741307$ & 0,0917393 & 0,154974463 & 0,034228026 \\
\hline 0,226409645 & $-0,374503036$ & 0,260617795 & 0,235914015 & $-0,069790466$ \\
\hline 0,496139795 & $-0,147851994$ & $-0,101089282$ & 0,050309732 & 0,464309645 \\
\hline$-0,037882248$ & 0,005832525 & 0,193739739 & 0,039785418 & 0,106496565 \\
\hline$-0,222531051$ & $-0,372333886$ & $-0,046794992$ & $-0,006864177$ & 0,065753603 \\
\hline$-0,047161924$ & 0,03905862 & 0,053866955 & $-0,106175717$ & $-0,057233974$ \\
\hline 0,011780055 & $-0,06694854$ & $-0,049564576$ & $-0,08838253$ & 0,156494469 \\
\hline$-0,343939141$ & $-0,287389474$ & 0,177306915 & 0,133589314 & 0,110186657 \\
\hline$-0,174751995$ & $-0,273356234$ & 0,015287307 & 0,112549966 & 0,025664261 \\
\hline$-0,112624099$ & $-0,16554592$ & 0,127710863 & 0,205020036 & 0,173522998 \\
\hline 0,197713127 & 0,023865637 & 0,086784175 & 0,01812202 & 0,294149031 \\
\hline$-0,032865424$ & $-0,101219136$ & 0,049738545 & $-0,008332177$ & 0,031173314 \\
\hline 0,461388352 & $-0,028643605$ & $-0,108627519$ & 0,037707864 & 0,305212776 \\
\hline 0,111164295 & $-0,296342849$ & $-0,099149823$ & 0,149977303 & $-0,05390619$ \\
\hline$-0,031854584$ & $-0,173385685$ & 0,092580203 & 0,064265425 & 0,200230075 \\
\hline$-0,036329188$ & 0,036046864 & 0,188112425 & 0,024805773 & 0,123283855 \\
\hline 0,492715731 & $-0,029902209$ & $-0,092375425$ & 0,015412525 & 0,382006068 \\
\hline 0,001258051 & $-0,058092113$ & 0,275647006 & 0,00387549 & 0,122696976 \\
\hline 0,051540119 & 0,00384704 & 0,116608852 & $-0,053290215$ & 0,02044656 \\
\hline$-0,002254909$ & $-0,129279844$ & 0,205526286 & 0,019224391 & 0,131614212 \\
\hline$-0,039372284$ & $-0,104933532$ & $-0,182704421$ & $-0,131728594$ & $-0,167139546$ \\
\hline 0,242031003 & $-0,166783462$ & 0,352557762 & 0,109054388 & $-0,165036748$ \\
\hline 0,055305245 & 0,802285075 & $-0,213606424$ & $-0,198029454$ & 0,052476097 \\
\hline$-0,063267876$ & $-0,295380083$ & 0,144351202 & 0,367080264 & $-0,224732014$ \\
\hline$-0,003648837$ & $-0,282188727$ & 0,132389838 & 0,223502687 & $-0,202722882$ \\
\hline$-0,262240328$ & 0,159768485 & $-0,091480161$ & $-0,26858178$ & $-0,039683441$ \\
\hline 1 & 0,016246285 & $-0,12282669$ & 0,003860124 & 0,016726755 \\
\hline 0,016246285 & 1 & $-0,074202798$ & $-0,32176452$ & 0,041524984 \\
\hline$-0,12282669$ & $-0,074202798$ & 1 & 0,548733105 & $-0,173900075$ \\
\hline 0,003860124 & $-0,32176452$ & 0,548733105 & 1 & $-0,336824449$ \\
\hline
\end{tabular}




$\begin{array}{rrrrr}0,016726755 & 0,041524984 & -0,173900075 & -0,336824449 & 1 \\ 0,535471333 & -0,2384987 & -0,034606638 & 0,075997816 & 0,219967853 \\ 0,400169952 & -0,191623816 & -0,050845668 & 0,026829384 & 0,194142256 \\ -0,080859525 & 0,010416745 & -0,069439181 & -0,227482345 & 0,354016155 \\ 0,018386438 & -0,104663168 & 0,018538794 & -0,146418565 & 0,383411104 \\ 0,358952131 & -0,291017612 & -0,164002371 & 0,022029232 & 0,184122047 \\ -0,069915102 & 0,126805597 & -0,089435509 & -0,176011844 & 0,147571601 \\ 0,56306339 & -0,252655334 & -0,040878616 & 0,073693235 & 0,247644047 \\ 0,526273925 & -0,191562444 & 0,044255213 & 0,150308373 & 0,13537165 \\ 0,39969458 & -0,119370206 & -0,027246235 & -0,06160257 & 0,500412124 \\ -0,087181162 & -0,160101833 & -0,163337199 & -0,089133037 & -0,134549005 \\ -0,09480964 & -0,084892975 & -0,093855532 & -0,080395425 & 0,202710345 \\ -0,000589604 & -0,210782456 & 0,016843913 & -0,216872063 & 0,050553674 \\ 0,553612333 & -0,239996398 & -0,07652717 & 0,097889087 & 0,231876219\end{array}$


EBC_Leucine.n.butyrate EBC_Propionate EBC_Ethanol

\begin{tabular}{|c|c|c|}
\hline 0,143248807 & 0,230240514 & 0,155596588 \\
\hline 0,128917011 & 0,145754956 & 0,210342952 \\
\hline$-0,104581562$ & $-0,119454172$ & $-0,049856551$ \\
\hline 0,149437094 & 0,223543097 & $-0,032134361$ \\
\hline 0,153467976 & 0,16957649 & $-0,080016089$ \\
\hline$-0,019659863$ & $-0,062902736$ & $-0,071440859$ \\
\hline 0,149303035 & 0,140465843 & $-0,043061242$ \\
\hline 0,105995859 & 0,095320418 & 0,043857467 \\
\hline 0,143648664 & 0,182474912 & 0,320143657 \\
\hline$-0,027299643$ & $-0,101171208$ & 0,000341475 \\
\hline 0,252617524 & 0,281775418 & 0,216896874 \\
\hline 0,276836973 & 0,252575901 & $-0,023191068$ \\
\hline 0,260361992 & 0,204056737 & $-0,015904752$ \\
\hline$-0,005525937$ & 0,134166635 & $-0,053374124$ \\
\hline$-0,080797294$ & $-0,188684488$ & 0,062530983 \\
\hline$-0,144727419$ & $-0,206636088$ & $-0,149159168$ \\
\hline 0,206704474 & 0,234625101 & $-0,042266516$ \\
\hline 0,009926779 & 0,03931064 & 0,17279445 \\
\hline 0,084121202 & 0,130117519 & $-0,03147818$ \\
\hline 0,141594631 & 0,07242506 & $-0,015146309$ \\
\hline 0,120019063 & 0,093176328 & $-0,074329973$ \\
\hline 0,430790064 & 0,305271325 & 0,104320598 \\
\hline 0,002731212 & 0,004645071 & 0,466833242 \\
\hline 0,072862477 & 0,170840224 & $-0,009326763$ \\
\hline$-0,057682529$ & $-0,115447264$ & 0,127976493 \\
\hline 0,058290209 & $-0,079972117$ & $-0,101624424$ \\
\hline$-0,026247657$ & 0,048496461 & 0,265862304 \\
\hline 0,171776828 & 0,175440352 & 0,076 \\
\hline 0,001399713 & 0,024540748 & 0,097530642 \\
\hline 0,008898546 & 0,073169822 & 26588 \\
\hline 0,094766303 & 0,053310429 & 0,278902708 \\
\hline 0,298861616 & 0,07247113 & $-0,084066141$ \\
\hline$-0,022146559$ & $-0,09382496$ & $-0,137097274$ \\
\hline 0,144631658 & 0,186614872 & 0,160767239 \\
\hline$-0,002834118$ & 0,003107374 & 0,482432671 \\
\hline 0,388287264 & 0,168186035 & $-0,046948899$ \\
\hline 0,23277613 & 0,292209982 & 0,292261128 \\
\hline 0,272695025 & 0,323740287 & 0,079514488 \\
\hline 0,241923598 & 0,277763178 & 0,158033169 \\
\hline 0,062328018 & 0,049322578 & $-0,026434195$ \\
\hline 0,24196318 & 0,207205605 & $-0,068184804$ \\
\hline$-0,240745192$ & $-0,215874536$ & $-0,052021379$ \\
\hline 0,244744282 & 0,297139994 & $-0,050767535$ \\
\hline 0,091840197 & 0,031182241 & $-0,089403436$ \\
\hline$-0,132245799$ & $-0,148570522$ & $-0,125451236$ \\
\hline 0,535471333 & 0,400169952 & $-0,080859525$ \\
\hline$-0,2384987$ & $-0,191623816$ & 0,010416745 \\
\hline$-0,034606638$ & $-0,050845668$ & $-0,069439181$ \\
\hline 0,075997816 & 0,026829384 & $-0,22748234$ \\
\hline
\end{tabular}

EBC_3.hydroxyisovalerate EBC_Lactate

$-0,009653255$

$-0,153614842$

$0,041466074-0,02116696$

$-0,221842898 \quad-0,284917091$

$-0,07444936-0,136611055$

$0,165599727 \quad 0,39482375$

$-0,072378514-0,012659507$

$-0,031671943 \quad 0,228938972$

$-0,095323679 \quad 0,152476355$

$-0,011547929 \quad 0,060937094$

$-0,039028406-0,077690866$

$0,189373761 \quad 0,202493871$

$0,105965159-0,004550533$

$0,186592263 \quad 0,265938606$

$-0,02353294 \quad 0,24674875$

$-0,243555916-0,067665085$

$-0,12133964 \quad-0,16263574$

$0,0317719 \quad 0,29100988$

$0,05191235 \quad 0,194519564$

$-0,09064769 \quad 0,034699004$

$0,246688518 \quad 0,22548335$

$0,348755856 \quad 0,104579546$

$0,071210171 \quad 0,403993226$

$0,235269001 \quad 0,017007861$

$0,228601804 \quad 0,150351319$

$-0,100818594 \quad-0,04027888$

$0,01461113 \quad 0,045694084$

$0,190618295 \quad 0,229487393$

$-0,047910334 \quad 0,197084674$

$0,095248095 \quad 0,135604273$

$0,166520833 \quad 0,038007707$

$0,19026846 \quad 0,020321259$

$-0,112039173 \quad 0,232735769$

$-0,191896332 \quad-0,146273715$

$0,211067442 \quad 0,213990384$

$0,243254125 \quad 0,020811741$

$0,034552917 \quad 0,362296788$

$0,129388535 \quad 0,15646795$

$0,178663946 \quad 0,087900779$

$0,192645548 \quad 0,150161321$

$-0,084280498 \quad 0,071571902$

$0,110924469 \quad 0,118981056$

$-0,147383526 \quad-0,246352385$

$0,080702754 \quad 0,111128956$

$-0,106365038 \quad 0,086001368$

$-0,110068083 \quad-0,117983116$

$0,018386438 \quad 0,358952131$

$-0,104663168 \quad-0,291017612$

$0,018538794 \quad-0,164002371$

$-0,146418565 \quad 0,022029232$ 


$\begin{array}{rrrrr}0,219967853 & 0,194142256 & 0,354016155 & 0,383411104 & 0,184122047 \\ 1 & 0,897710758 & 0,182292467 & 0,423083143 & 0,584078394 \\ 0,897710758 & 1 & 0,349644438 & 0,508369721 & 0,511938003 \\ 0,182292467 & 0,349644438 & 1 & 0,542847698 & 0,134467741 \\ 0,423083143 & 0,508369721 & 0,542847698 & 1 & 0,41675234 \\ 0,584078394 & 0,511938003 & 0,134467741 & 0,41675234 & 1 \\ -0,04316878 & 0,052735066 & 0,196913169 & 0,22882454 & 0,147361331 \\ 0,976642515 & 0,867472486 & 0,193842007 & 0,413058144 & 0,569567052 \\ 0,933116351 & 0,893266352 & 0,090815291 & 0,402234584 & 0,469539336 \\ 0,666925043 & 0,582376035 & 0,363630876 & 0,702953695 & 0,576667983 \\ 0,280305877 & 0,491268185 & 0,028928586 & 0,043307551 & 0,260772027 \\ 0,018220458 & -0,006167552 & 0,144379099 & 0,620915669 & 0,305891714 \\ 0,344596536 & 0,289414492 & 0,139918406 & 0,400906039 & 0,185802705 \\ 0,895616486 & 0,67840208 & 0,075515086 & 0,258880633 & 0,606823132\end{array}$


EBC_Acetoine

$-0,018061341$

$-0,063759586$

0,018238863

$-0,035399585$

0,004641835

0,026050699

$-0,116757887$

$-0,043708743$

$-0,121073224$

$-0,175993297$

$-0,168497034$

$-0,083349899$

$-0,08267295$

0,154507795

$-0,154676748$

0,130555476

0,306058759

0,3264403

0,43473455

$-0,005796731$

$-0,039736205$

0,078922139

0,052800653

$-0,169257527$

$-0,083943483$

0,078196937

0,050477098

0,209807388

0,309611408

0,319788523

$-0,101782019$

$-0,068783487$

$-0,018512811$

0,11264509

0,057780369

0,097976764

0,237189815

0,094780651

0,174925966

$-0,117538661$

$-0,110081064$

0,195726739

$-0,117876882$

$-0,189960888$

$-0,047440352$

$-0,069915102$

0,126805597

$-0,089435509$

$-0,176011844$
EBC_n.Butyrate

0,061812172

0,087056071

$-0,138980484$

0,10201256

0,178375069

$-0,036481894$

0,073088956

0,061469194

0,082530576

$-0,035536854$

0,23302637

0,256852462

0,284714887

0,016719867

$-0,084760795$

$-0,140558169$

0,148842949

0,03473051

0,006153109

0,131027437

0,131535843

0,453309713

0,03210388

0,103059705

$-0,066137761$

0,053177431

0,02376957

0,169483546

0,056920269

0,010838431

0,09716391

0,315813296

$-0,033044372$

0,189270164

0,027174497

0,412606817

0,162899493

0,184100039

0,182189647

0,021632867

0,252000041

$-0,230588196$

0,216155242

0,060806151

$-0,122073581$

0,56306339

$-0,252655334$

$-0,040878616$

0,073693235
BC_Acetate

0,058671932

0,058837161

$-0,117208072$

0,155207047

0,129683475

$-0,06582845$

0,006967268

0,00884082

0,009803816

$-0,06001886$

0,158790637

0,350814664

0,199688951

0,025858212

$-0,14853928$

$-0,088571176$

0,148330213

0,018008454

0,072205446

0,142970908

0,161849064

0,343737405

$-0,051876202$

0,07757041

$-0,135556856$

0,038605239

$-0,045676662$

0,149474351

0,069678425

$-0,005823039$

$-0,026106328$

0,210124259

$-0,065834954$

0,091365598

$-0,058707951$

0,294301535

0,160425233

0,183743512

0,147819485

$-0,019225902$

0,323759138

$-0,207047245$

0,333787419

0,027439333

$-0,114399435$

0,526273925

$-0,191562444$

0,044255213

0,150308373
BC_Acetone

$-0,099828463$

0,012281395

$-0,148087977$

$-0,098121429$

0,224812875

$-0,06245979$

$-0,102542934$

$-0,038834513$

$-0,110640324$

$-0,149215656$

0,193979706

0,030743393

0,321599916

$-0,004011023$

$-0,148804951$

$-0,032401486$

0,030085358

0,149961904

$-0,174449353$

0,240603798

0,306572894

0,568183669

0,264931287

0,080402825

$-0,170705905$

0,147750844

0,049695274

0,135822158

0,187212121

0,13808

0,155104832

0,46483366

$-0,046562687$

0,083963236

0,272247268

0,626795209

0,058651673

0,013470001

0,064608478

$-0,107720262$

0,056314051

$-0,141746713$

$-0,012723556$

$-0,089265558$

$-0,089254255$

0,39969458

$-0,119370206$

$-0,027246235$

$-0,06160257$
EBC_Trimethylamine EBC_Methanol

0,297597699

$-0,205428$

$-0,003201564 \quad 0,015392546$

$-0,138587536-0,195228139$

$0,110774572 \quad-0,177915312$

$0,105759653 \quad 0,157112548$

$-0,06720949 \quad 0,079439523$

$0,420694725 \quad-0,010490143$

$0,134161868 \quad-0,049795168$

$0,264264056-0,140215833$

$0,081597205 \quad-0,066063774$

$0,108076126 \quad 0,130371845$

9,96E-05 -0,027624145

$-0,014462525 \quad 0,053026921$

$0,277618762 \quad 0,036432337$

$-0,097560984-0,086536657$

$-0,206913206 \quad-0,136071787$

$0,437080947-0,029735789$

$0,039347967 \quad-0,105701487$

$0,36742315 \quad-0,235871535$

$-0,095321503 \quad 0,374623157$

$-0,161111235 \quad 0,367110736$

$-0,104064049-0,020970496$

$-0,181996522 \quad 0,061155669$

$0,288044451 \quad 0,259575762$

$0,062443638 \quad-0,185477201$

$-0,09478963 \quad-0,136082578$

$0,191561935 \quad 0,218550146$

$0,14444333-0,282419681$

$-0,043338404 \quad-0,022807982$

$-0,069759629 \quad 0,11675271$

$-0,049034708 \quad 0,185865807$

$-0,285391008-0,112233525$

$-0,012270893 \quad-0,179728566$

$0,157753452 \quad 0,349430634$

$-0,185445736$

$-0,26310057$

0,314156736

0,383034149

0,343715361

0,230778508

$-0,078872948$

$-0,09210502$

0,206489573

0,151553396

$-0,136086358$

$-0,087181162$

$-0,160101833$

$-0,163337199$

$-0,089133037$
0,060902552

$-0,042440463$

$-0,169739251$

0,014373682

0,053844953

$-0,065513935$

0,006041944

$-0,037553268$

$-0,006139023$

$-0,017655662$

$-0,053946195$

$-0,09480964$

$-0,084892975$

$-0,093855532$

$-0,080395425$ 


$\begin{array}{rrrrrr}0,147571601 & 0,247644047 & 0,13537165 & 0,500412124 & -0,134549005 & 0,202710345 \\ -0,04316878 & 0,976642515 & 0,933116351 & 0,666925043 & 0,280305877 & 0,018220458 \\ 0,052735066 & 0,867472486 & 0,893266352 & 0,582376035 & 0,491268185 & -0,006167552 \\ 0,196913169 & 0,193842007 & 0,090815291 & 0,363630876 & 0,028928586 & 0,144379099 \\ 0,22882454 & 0,413058144 & 0,402234584 & 0,702953695 & 0,043307551 & 0,620915669 \\ 0,147361331 & 0,569567052 & 0,469539336 & 0,576667983 & 0,260772027 & 0,305891714 \\ 1 & -0,056708619 & 0,039599856 & 0,22442167 & 0,004899105 & 0,007533279 \\ -0,056708619 & 1 & 0,92874807 & 0,689039997 & 0,213185475 & 0,051602043 \\ 0,039599856 & 0,92874807 & 1 & 0,603326648 & 0,24360785 & -0,037231146 \\ 0,22442167 & 0,689039997 & 0,603326648 & 1 & -0,116074717 & 0,359573545 \\ 0,004899105 & 0,213185475 & 0,24360785 & -0,116074717 & 1 & -0,144953321 \\ 0,007533279 & 0,051602043 & -0,037231146 & 0,359573545 & -0,144953321 & 1 \\ -0,216790149 & 0,28210432 & 0,177216519 & 0,160965297 & 0,24456309 & 0,2680657 \\ -0,060398137 & 0,88971655 & 0,792285908 & 0,699797457 & 0,114593323 & -0,010556025\end{array}$




\begin{tabular}{|c|c|}
\hline & te \\
\hline 0,394915689 & $-0,0558573$ \\
\hline 11 & \\
\hline 0,030610535 & $-0,1$ \\
\hline 0,076380321 & 5372 \\
\hline 33881 & 209346 \\
\hline 022 & \\
\hline 0,410627547 & 0,0965 \\
\hline 836 & \\
\hline & \\
\hline 0,119825089 & 0,01 \\
\hline 906 & \\
\hline 353 & \\
\hline 284 & \\
\hline$-0,30$ & $-0,0$ \\
\hline 48 & $-0,0$ \\
\hline$-0,2$ & $-0,0$ \\
\hline 015 & \\
\hline$-0,2 \varepsilon$ & 0,0 \\
\hline & $-0,0$ \\
\hline 0,0 & \\
\hline 745 & 70 \\
\hline$-0,1$ & \\
\hline$-0,0$ & \\
\hline 48 & \\
\hline 009 & 0,0 \\
\hline 992 & \\
\hline 62 & $-0,0$ \\
\hline$-0,07$ & \\
\hline$-0,31$ & \\
\hline-0 , & $-0,0$ \\
\hline 39 & \\
\hline 507 & 0,4 \\
\hline$-0,1$ & ח \\
\hline & \\
\hline$-0,0$ & \\
\hline-0, & \\
\hline & \\
\hline 382 & 0,0 \\
\hline 0,3 & 0,0 \\
\hline & 0,0 \\
\hline & \\
\hline$-0,2$ & $-0,2$ \\
\hline & 0,1 \\
\hline 3961 & \\
\hline & $-0,1$ \\
\hline$-0,000$ & \\
\hline$-0,210782456$ & $-0,23999639$ \\
\hline & \\
\hline$-0,216$ & 0,097889 \\
\hline
\end{tabular}




$\begin{array}{rr}0,050553674 & 0,231876219 \\ 0,344596536 & 0,895616486 \\ 0,289414492 & 0,67840208 \\ 0,139918406 & 0,075515086 \\ 0,400906039 & 0,258880633 \\ 0,185802705 & 0,606823132 \\ -0,216790149 & -0,060398137 \\ 0,28210432 & 0,88971655 \\ 0,177216519 & 0,792285908 \\ 0,160965297 & 0,699797457 \\ 0,24456309 & 0,114593323 \\ 0,2680657 & -0,010556025 \\ 1 & 0,174940363 \\ 0,174940363 & 1\end{array}$


Supplementary Table S6. Pearson's correlations between metabolites among se

Urine_Leucine

Urine_Leucine

Urine_Valine

Urine_Isobutyrate

Urine_Alanine

Urine_Pyruvate

Urine_Citrate

Urine_Trimethyamine

Urine_Glycine

Urine_Creatinine

Urine_Trigonelline

Urine_cis.Aconitate

Urine_p.Hydroxyphenylacetate

Urine_Phenylacetylglycine

Urine_Hippurate

Urine_Methylnicotinamide

Serum_Formate

Serum_Phenylalanine

Serum_Histidine

Serum_Tyrosine

Serum_Glucose

Serum_Mannose

Serum_Proline

Serum_Lactate

Serum_Creatinine

Serum_Creatine

Serum_Glycerol

Serum_Glycine

Serum_Citrate

Serum_Glutamine

Serum_Glutamate

Serum_Pyruvate

Serum_Acetoacetate

Serum_Acetate

Serum_Alanine

Serum_Threonine.Lactate

Serum_3.hydroxybutyrate

Serum_Valine

Serum_Isoleucine

Serum_Leucine

Sputum_propionato

Sputum_lactate

Sputum_acetoin

Sputum_alanine

Sputum_acetate

Sputum_acetone

Sputum_succinate

Sputum_unk

Sputum_taurine

Sputum_glycine

0
$6,15 \mathrm{E}-06$
$3,16 \mathrm{E}-05$
$3,72 \mathrm{E}-06$

0,398439135

0,037821985

0,000488638

$8,29 \mathrm{E}-05$

0,000177921

0,991435713

0,072416435

0,014273571

0,882239504

0,971699107

0,897309907

0,565765152

0,490952062

0,151649208

0,339591627

0,452618261

0,812083777

0,88568171

0,618640505

0,093717225

0,353846912

0,075775927

0,038199058

0,916234547

0,003056405

0,686243587

0,826007504

0,470273434

0,097138963

0,382596989

0,587337551

0,542883613

0,37173781

0,000342616

0,083114164

0,217615562

0,846408517

0,287902821

0,47703496

0,973311229

0,436966035

0,434811297

0,224300775

0,153075009
0,448367122
Urine_Valine U

$$
\text { 6,15E-06 }
$$

0

7,15E-11

1,93E-06

0,084571274

4,67E-05

0,228602623

1,26E-07

2,27E-06

0,297220229

0,005051634

0,047066124

0,078391922

0,598179542

0,018155321

0,035247265

0,199663508

0,0256

0,367443525

0,339545233

0,317417486

0,940512426

0,549091725

0,000530319

0,799370029

0,002255549

0,004076541

0,042192807

4,96E-05

0,309565463

0,055916514

0,858590831

0,480519751

0,425365937

0,6481484

0,798971172

0,368266772

0,330184879

0,890600144

0,837905835

0,091101254

0,558022676

0,283104644

0,901515744

0,919055303

0,083442757

0,5226045

0,858748264

0,541675422
Urine_Isobutyrate Urine_Alanine

$\begin{array}{cc}3,16 \mathrm{E}-05 & 3,72 \mathrm{E}-06 \\ 7,15 \mathrm{E}-11 & 1,93 \mathrm{E}-06 \\ 0 & 2,33 \mathrm{E}-09 \\ 2,33 \mathrm{E}-09 & 0\end{array}$

$0,041320547 \quad 0,592645978$

8,24E-08 9,50E-06

$0,622253677 \quad 0,681832727$

$0,000639941 \quad 0,001630719$

$0,009730184 \quad 0,041541343$

$0,654802297 \quad 0,817074377$

$0,599857218 \quad 0,683214205$

$0,492332935 \quad 0,107839074$

$0,03449653 \quad 0,791033661$

$0,537711605 \quad 0,389447256$

$0,11605733 \quad 0,198693372$

$0,812261402 \quad 0,9778736$

$0,021368317 \quad 0,109156695$

$0,05553943 \quad 0,00020188$

$0,311308467 \quad 0,537860149$

$0,431776594 \quad 0,990063412$

$0,687812226 \quad 0,433548445$

$0,597995178 \quad 0,31210493$

$0,447864924 \quad 0,036784321$

4,72E-07 $\quad 0,008046353$

$0,444217198 \quad 0,588426137$

$0,004155571 \quad 0,002499224$

2,77E-06 1,48E-07

$0,153996626 \quad 0,112998916$

$0,000346763 \quad 4,68 \mathrm{E}-06$

$0,866216226 \quad 0,769919456$

$0,823306588 \quad 0,820338657$

$0,832739803 \quad 0,339591029$

$0,587112739 \quad 0,125009009$

$0,0087336 \quad 0,041668403$

$0,383671844 \quad 0,016183354$

$0,801210543 \quad 0,330276065$

$0,243249943 \quad 0,118675784$

$0,925857751 \quad 0,371590251$

$0,102495724 \quad 0,255279929$

$0,949889125 \quad 0,797969941$

$0,536894228 \quad 0,430572299$

$0,02373043 \quad 0,922003494$

$0,000497132 \quad 0,247906337$

$0,520469865 \quad 0,583819908$

$0,858569339 \quad 0,372994$

$0,529133618 \quad 0,133848698$

$0,010036186 \quad 0,577906683$

$0,985405807 \quad 0,314207222$

$0,563836121 \quad 0,82192991$ 


Sputum_formate
EBC_Leucine.n.butyrate
EBC_Propionate
EBC_Ethanol
EBC_3.hydroxyisovalerate
EBC_Lactate
EBC_Acetoine
EBC_n.Butyrate
EBC_Acetate
EBC_Acetone
EBC_Trimethylamine
EBC_Methanol
EBC_Phenol
EBC_Formate

$\begin{array}{cccc}0,804288324 & 0,647283152 & 0,803108718 & 0,327376292 \\ 0,292230134 & 0,343675971 & 0,443038525 & 0,271659474 \\ 0,087799629 & 0,283780099 & 0,380542474 & 0,09769245 \\ 0,252164811 & 0,119702021 & 0,715182717 & 0,814124502 \\ 0,943707625 & 0,761557991 & 0,100336628 & 0,585533418 \\ 0,258330669 & 0,876944524 & 0,033306689 & 0,315396568 \\ 0,894888587 & 0,640609262 & 0,89386138 & 0,795625523 \\ 0,650865341 & 0,523481804 & 0,306996049 & 0,454382242 \\ 0,667538907 & 0,666657525 & 0,389627542 & 0,253368855 \\ 0,464150148 & 0,928417527 & 0,27605977 & 0,471862882 \\ 0,025912299 & 0,981316853 & 0,308379139 & 0,416349891 \\ 0,12879765 & 0,910350933 & 0,14932529 & 0,189566733 \\ 0,002594529 & 0,045407925 & 0,822792933 & 0,575817271 \\ 0,682620524 & 0,799958276 & 0,418609411 & 0,851798862\end{array}$


rum, urine, EBC, and sputum supernatant ( $P$ values)

\begin{tabular}{|c|c|c|c|c|}
\hline Jrine_Pyruvate & Urine_Citrate & Urine_Trimethyamine & Urine_Glycine & Urine_Creatinir \\
\hline 0,398439135 & 0,037821985 & 0,000488638 & $8,29 E-05$ & 0,000177921 \\
\hline 0,084571274 & 4,67E-05 & 0,228602623 & $1,26 \mathrm{E}-07$ & 2,27E-06 \\
\hline 0,041320547 & $8,24 \mathrm{E}-08$ & 0,622253677 & 0,000639941 & 0,009730184 \\
\hline 0,592645978 & $9,50 E-06$ & 0,681832727 & 0,001630719 & 0,041541343 \\
\hline 0 & 0,650076628 & 0,028227436 & 0,461684912 & 0,071366181 \\
\hline 0,650076628 & 0 & 0,30099916 & $4,55 \mathrm{E}-07$ & 0,002287213 \\
\hline 0,028227436 & 0,30099916 & 0 & 0,013036303 & 0,003446531 \\
\hline 0,461684912 & $4,55 \mathrm{E}-07$ & 0,013036303 & 0 & $5,77 \mathrm{E}-06$ \\
\hline 0,071366181 & 0,002287213 & 0,003446531 & $5,77 E-06$ & 0 \\
\hline 0,552718368 & 0,503069485 & 0,273805394 & 0,691054342 & 0,487815971 \\
\hline 0,944429428 & 0,319823342 & 0,00103164 & 0,039499382 & 0,000366575 \\
\hline 0,522867356 & 0,729646858 & 0,237394142 & 0,068170252 & 0,329976337 \\
\hline $9,75 E-16$ & 0,178284497 & 0,019130309 & 0,423025684 & 0,031952302 \\
\hline 0,011090505 & 0,680636584 & 0,899606414 & 0,99491526 & 0,208112913 \\
\hline 0,000135885 & 0,041309195 & 0,543833209 & 0,003955752 & 0,000320333 \\
\hline 0,664034932 & 0,90494235 & 0,505468799 & 0,09134538 & 0,005321065 \\
\hline 0,339787322 & 0,074014781 & 0,00082571 & 0,606878234 & 0,802301208 \\
\hline 0,048116763 & 0,014881724 & 0,390925757 & 0,416929521 & 0,365268791 \\
\hline 0,266829805 & 0,748188709 & 0,215253085 & 0,556316419 & 0,82173936 \\
\hline 0,914565349 & 0,889673149 & 0,412243001 & 0,176214703 & 0,530085088 \\
\hline 0,449153317 & 0,838084414 & 0,749982 & 0,988066805 & 0,312483916 \\
\hline 0,278352313 & 0,029456631 & 0,17536 & 0,547083266 & 0186 \\
\hline 0,416552307 & 0,016254747 & 0,770453834 & 0,143631526 & 0,727447028 \\
\hline 0,000171165 & $5,76 \mathrm{E}-08$ & 0,037684158 & $1,02 \mathrm{E}-05$ & 455383 \\
\hline 0,446749715 & 0,047177776 & 0,8097 & 0,069492836 & 87401 \\
\hline 0,384403786 & 0,195654097 & 0,527531666 & 0,186631637 & 0,09087613 \\
\hline 0,0721069 & 0,000615424 & 0,403314692 & 0,039411014 & 789085 \\
\hline 0,004914769 & 0,543021654 & 0,059592788 & 0,416551475 & 5736 \\
\hline 0,003236008 & 0,000 & 0,9 & 0,002764736 & 0403 \\
\hline 0,483425584 & 0,0701 & 0,276084148 & 0,47104733 & 0238 \\
\hline 0,859488055 & 0,829460312 & 0,267338419 & 0,779759528 & 241306 \\
\hline 0,684607732 & 0,321 & 25 & 0,707792011 & 3513 \\
\hline 0,530707271 & 0,516542677 & 0,750848738 & 7599578 & 2605 \\
\hline 0,056745717 & 0,278307348 & 0,026592649 & 0,732505213 & 0,794948829 \\
\hline 0,388283778 & 0,011057623 & 4123 & 0,127935585 & 3684 \\
\hline 0,41403093 & 0,465410902 & 949 & 0,944014917 & 0,112728413 \\
\hline 0,454597965 & 0,05998955 & 0,031345942 & 0,260169663 & 0,018712565 \\
\hline 0,708061451 & 0,690285757 & 0,003543113 & 0,172336866 & 0,054382846 \\
\hline 0,933684283 & 0,062975097 & 0,001889823 & 0,53131784 & 0,213740761 \\
\hline 0,915804833 & 0,750170618 & 0,010773968 & 0,375787704 & 0,005017084 \\
\hline 0,555978917 & 0,637149396 & 0,463031909 & 0,418868327 & 0,170468443 \\
\hline 0,030595625 & 0,15530533 & 0,808946565 & 0,259725427 & 0,752163948 \\
\hline 0,446178067 & 0,00020027 & 0,517106521 & 0,010440889 & 0,172549014 \\
\hline 0,655981481 & 0,624937309 & 0,174908788 & 0,848749623 & 0,036119824 \\
\hline 0,081127906 & 0,755820158 & 0,244002855 & 0,257992563 & 0,876507818 \\
\hline 0,335675926 & 0,399743875 & 0,793689 & 0,011921293 & 0,438180798 \\
\hline 0,009935104 & 0,209387766 & 0,129211263 & 0,956791726 & 0,302401993 \\
\hline 0,289542443 & 0,3512 & 50212 & 0,159161566 & 0,409921066 \\
\hline 0,267087395 & 0,841923423 & 0,408177677 & 0,538536681 & 0,110501481 \\
\hline
\end{tabular}




$\begin{array}{lllll}0,733897698 & 0,331497791 & 0,955560946 & 0,847537879 & 0,284888516 \\ 0,258791626 & 0,885645324 & 0,272094621 & 0,43686133 & 0,29087103 \\ 0,211502323 & 0,645113804 & 0,301804039 & 0,484665753 & 0,178285955 \\ 0,557726631 & 0,600817066 & 0,752671235 & 0,748247237 & 0,016155538 \\ 0,222568288 & 0,596034861 & 0,816752726 & 0,484650743 & 0,932682372 \\ 0,002601069 & 0,926219714 & 0,089657977 & 0,261918434 & 0,655495102 \\ 0,972914615 & 0,848853886 & 0,391463759 & 0,749072969 & 0,374072855 \\ 0,188406631 & 0,78951777 & 0,592422752 & 0,652678382 & 0,545374581 \\ 0,340790333 & 0,629786204 & 0,959355083 & 0,948438578 & 0,942831089 \\ 0,095753216 & 0,647447397 & 0,45202737 & 0,776285064 & 0,416918463 \\ 0,437889637 & 0,622604005 & 0,001244725 & 0,3242326 & 0,049055392 \\ 0,247516016 & 0,560577454 & 0,938836292 & 0,715518538 & 0,302673937 \\ 0,935381617 & 0,537004739 & 0,001669685 & 0,140502225 & 0,000550503 \\ 0,129214089 & 0,827424481 & 0,479040158 & 0,704103306 & 0,801702063\end{array}$




\begin{tabular}{|c|c|c|c|}
\hline Urine_Trigonelline & Urine_cis.Aconitate & Urine_p.Hydroxyphenylacetate & Urine_Phenylacetylglycine \\
\hline 0,991435713 & 0,072416435 & 0,014273571 & 0,882239504 \\
\hline 0,297220229 & 0,005051634 & 0,047066124 & 0,078391922 \\
\hline 0,654802297 & 0,599857218 & 0,492332935 & 0,03449653 \\
\hline 0,817074377 & 0,683214205 & 0,107839074 & 0,791033661 \\
\hline 0,552718368 & 0,944429428 & 0,522867356 & $9,75 E-16$ \\
\hline 0,503069485 & 0,319823342 & 0,729646858 & 0,178284497 \\
\hline 0,273805394 & 0,00103164 & 0,237394142 & 0,019130309 \\
\hline 0,691054342 & 0,039499382 & 0,068170252 & 0,423025684 \\
\hline 0,487815971 & 0,000366575 & 0,329976337 & 0,031952302 \\
\hline 0 & 0,081832765 & 0,465514828 & 0,252326026 \\
\hline 0,081832765 & 0 & 0,039075948 & 0,730816152 \\
\hline 0,465514828 & 0,039075948 & 0 & 0,769784922 \\
\hline 0,252326026 & 0,730816152 & 0,769784922 & 0 \\
\hline 0,003774486 & 0,361326144 & 0,337751281 & 0,33801031 \\
\hline 0,336934406 & 0,755669747 & 0,630707791 & $8,54 \mathrm{E}-05$ \\
\hline 0,791831661 & 0,00725009 & 0,760378582 & 0,570901874 \\
\hline 0,555800567 & 0,367170347 & 0,839941134 & 0,667236851 \\
\hline 0,627414253 & 0,737731171 & 0,423074404 & 0,222121918 \\
\hline 0,567087433 & 0,585954263 & 0,972006599 & 0,145485359 \\
\hline 0,818564302 & 0,017006025 & 0,005083659 & 0,64670308 \\
\hline 0,532252937 & 0,015250075 & 0,066784659 & 0,218748652 \\
\hline 0,21086128 & 0,081542471 & 0,589713565 & 0,015696555 \\
\hline 0,701973635 & 0,008131741 & 0,685473838 & 0,71927251 \\
\hline 0,688964299 & 0,385737023 & 0,131629623 & 0,001290039 \\
\hline 0,001610282 & 0,02686604 & 0,553212326 & 0,598524745 \\
\hline 0,040633972 & 0,009771421 & 0,91680474 & 0,039928124 \\
\hline 0,58103911 & 0,852331984 & 0,137001276 & 0,259302997 \\
\hline 0,106747813 & 0,159779494 & 0,197859819 & 0,008364475 \\
\hline 0,418989985 & 0,11549038 & 0,147990069 & 0,011060347 \\
\hline 0,054440361 & 0,000494221 & 0,236027367 & 0,972242076 \\
\hline 0,941731913 & 0,000207472 & 0,538911481 & 0,90549866 \\
\hline 0,45808865 & 0,651434983 & 0,887773035 & 0,20863056 \\
\hline 0,790311255 & 0,674484471 & 0,097047168 & 0,081590975 \\
\hline 0,193047777 & 0,004511371 & 0,891843279 & 0,323440846 \\
\hline 0,63367472 & 0,011434683 & 0,786896933 & 0,677311817 \\
\hline 0,369259791 & 0,729700086 & 0,848755604 & 0,025918919 \\
\hline 0,943329339 & 0,004842318 & 0,32643852 & 0,434291028 \\
\hline 0,892108128 & 0,019913483 & 0,023677649 & 0,604221819 \\
\hline 0,897567149 & 0,005553855 & 0,089871353 & 0,889905345 \\
\hline 0,918245888 & 0,249475953 & 0,252670952 & 0,878415345 \\
\hline 0,924772579 & 0,019532451 & 0,025236419 & 0,972921015 \\
\hline 0,410289767 & 0,172281285 & 0,847029911 & 0,003660995 \\
\hline 0,302164328 & 0,287337519 & 0,574404048 & 0,689430055 \\
\hline 0,45218379 & 0,067565 & 0,349962278 & 0,887329141 \\
\hline 0,773525093 & 0,772963378 & 0,408075926 & 0,04400457 \\
\hline 0,247537366 & 0,013657375 & 0,00120318 & 0,12855208 \\
\hline 0,999922446 & 0,132480562 & 0,645226083 & 0,001143426 \\
\hline 0,603669454 & 0,286220258 & 0,860705468 & 0,230236684 \\
\hline 0,830018441 & 0,944292295 & 0,726034577 & 0,342186095 \\
\hline
\end{tabular}




$\begin{array}{cccc}0,200432423 & 0,929877915 & 0,410984862 & 0,161466568 \\ 0,841698546 & 0,060330471 & 0,038876476 & 0,052623852 \\ 0,458131611 & 0,035387848 & 0,060374223 & 0,131426114 \\ 0,998007102 & 0,108344544 & 0,865281789 & 0,907380597 \\ 0,775197233 & 0,16215332 & 0,436994905 & 0,168523776 \\ 0,569265371 & 0,134470896 & 0,973447173 & 0,047585774 \\ 0,194471946 & 0,214467095 & 0,541378478 & 0,544679158 \\ 0,794850195 & 0,083923507 & 0,056010815 & 0,0334375 \\ 0,660367055 & 0,242438443 & 0,008028367 & 0,140067924 \\ 0,272378498 & 0,151995606 & 0,822036304 & 0,015651458 \\ 0,549944194 & 0,427863623 & 0,999418984 & 0,915747301 \\ 0,628559952 & 0,338211605 & 0,839841488 & 0,697912096 \\ 0,379054451 & 0,003384687 & 0,138284322 & 0,371925648 \\ 0,921846973 & 0,207209667 & 0,404710223 & 0,01400291\end{array}$




\begin{tabular}{|c|c|c|c|c|}
\hline Urine_Hippurate & Urine_Methylnicotinamide & Serum_Formate & Serum_Phenylalanine & Serum_Histidine \\
\hline 0,971699107 & 0,897309907 & 0,565765152 & 0,490952062 & 0,151649208 \\
\hline 0,598179542 & 0,018155321 & 0,035247265 & 0,199663508 & 0,0256 \\
\hline 0,537711605 & 0,11605733 & 0,812261402 & 0,021368317 & 0,05553943 \\
\hline 0,389447256 & 0,198693372 & 0,9778736 & 0,109156695 & 0,00020188 \\
\hline 0,011090505 & 0,000135885 & 0,664034932 & 0,339787322 & 0,048116763 \\
\hline 0,680636584 & 0,041309195 & 0,90494235 & 0,074014781 & 0,014881724 \\
\hline 0,899606414 & 0,543833209 & 0,505468799 & 0,00082571 & 0,390925757 \\
\hline 0,99491526 & 0,003955752 & 0,09134538 & 0,606878234 & 0,416929521 \\
\hline 0,208112913 & 0,000320333 & 0,005321065 & 0,802301208 & 0,365268791 \\
\hline 0,003774486 & 0,336934406 & 0,791831661 & 0,555800567 & 0,627414253 \\
\hline 0,361326144 & 0,755669747 & 0,00725009 & 0,367170347 & 0,737731171 \\
\hline 0,337751281 & 0,630707791 & 0,760378582 & 0,839941134 & 0,423074404 \\
\hline 0,33801031 & $8,54 \mathrm{E}-05$ & 0,570901874 & 0,667236851 & 0,222121918 \\
\hline 0 & 0,04381475 & 0,148620541 & 0,041569989 & 0,262602102 \\
\hline 0,04381475 & 0 & 0,010882656 & 0,160205567 & 0,862634256 \\
\hline 0,148620541 & 0,010882656 & 0 & 0,25940724 & 0,365036845 \\
\hline 0,041569989 & 0,160205567 & 0,25940724 & 0 & $3,80 \mathrm{E}-05$ \\
\hline 0,262602102 & 0,862634256 & 0,365036845 & $3,80 \mathrm{E}-05$ & 0 \\
\hline 0,644974697 & 0,763479711 & 0,093668221 & 1,07E-09 & 0,117367157 \\
\hline 0,400490358 & 0,558770937 & 0,196510816 & 0,612303026 & 0,941484368 \\
\hline 0,950056536 & 0,012361314 & 0,079061931 & 0,828355515 & 0,975497602 \\
\hline 0,332752883 & 0,860136536 & 0,820760696 & 0,117710481 & 0,013394188 \\
\hline 0,24012597 & 0,610107676 & 0,581170849 & 0,551859802 & 0,029096824 \\
\hline 0,107197653 & 0,00048755 & 0,255646462 & 0,128833918 & 0,308092804 \\
\hline 0,014594798 & $1,15 \mathrm{E}-05$ & 0,621770908 & 0,573339965 & 0,088501185 \\
\hline 0,009995566 & 0,25928607 & 0,101444596 & 0,391185333 & 0,136811003 \\
\hline 0,572865945 & 0,846559827 & 0,144554056 & 0,019371941 & 0,000358889 \\
\hline 0,957297606 & 0,053449558 & 0,009182904 & 0,00048827 & 0,000570279 \\
\hline 0,355338376 & 0,057536998 & 0,078473096 & 0,000906612 & $7,52 \mathrm{E}-11$ \\
\hline 0,242842526 & 0,261616595 & 0,828948674 & 0,027761348 & 0,023805081 \\
\hline 0,176365336 & 0,446909555 & 0,696821753 & 0,956298305 & 0,373223496 \\
\hline 0,509283829 & 0,0404585 & 0,797248909 & 0,664147512 & 0,484305452 \\
\hline 0,275119827 & 0,13120018 & 0,001520974 & 0,406420391 & 0,851552078 \\
\hline 0,259167845 & 0,126344209 & 0,304259955 & 0,001435913 & 0,022914362 \\
\hline 0,226178741 & 0,719909636 & 0,634385553 & 0,54049008 & 0,016453689 \\
\hline 0,957856293 & 0,608490637 & 0,260266919 & 0,718189758 & 0,113392486 \\
\hline 0,6571612 & 0,146246896 & 0,466342018 & $1,16 \mathrm{E}-05$ & 1,47E-05 \\
\hline 0,49378496 & 0,981093398 & 0,964431566 & 9,39E-05 & 0,066369081 \\
\hline 0,77154555 & 0,975604104 & 0,798500985 & $1,26 \mathrm{E}-08$ & 0,000190972 \\
\hline 0,998768442 & 0,967016563 & 0,433399622 & 0,872916385 & 0,079149346 \\
\hline 0,392944397 & 0,702037875 & 0,750866891 & 0,676738125 & 0,899518042 \\
\hline 0,298631409 & 0,016004939 & 0,752913357 & 0,64999811 & 0,411681573 \\
\hline 0,253537095 & 0,138701632 & 0,917925764 & 0,043928613 & 0,585800648 \\
\hline 0,620593395 & 0,63603831 & 0,277795038 & 0,647799319 & 0,221626292 \\
\hline 0,281640263 & 0,651727877 & 0,252898656 & 0,352276183 & 0,162454315 \\
\hline 0,374771095 & 0,523896307 & 0,25578183 & 0,472140836 & 0,936214029 \\
\hline 0,076060671 & 0,010095759 & 0,715187978 & 0,03325506 & 0,796029475 \\
\hline 0,278998678 & 0,512767091 & 0,298461459 & 0,553748091 & 0,052636981 \\
\hline 0,103277177 & 0,699817351 & 0,359150113 & 0,179890135 & 0,141675058 \\
\hline
\end{tabular}




$\begin{array}{ccccc}0,964160052 & 0,908143942 & 0,984266533 & 0,670772731 & 0,255970489 \\ 0,967758337 & 0,553874948 & 0,301153206 & 0,137533552 & 0,943758699 \\ 0,324215252 & 0,163715243 & 0,137666628 & 0,090824905 & 0,779884448 \\ 0,696029724 & 0,647072102 & 0,286433184 & 0,763794353 & 0,215976377 \\ 0,863314694 & 0,070475301 & 0,386761054 & 0,821322436 & 0,712004804 \\ 0,066756079 & 0,620242244 & 0,244610718 & 0,034510425 & 0,162796218 \\ 0,255539943 & 0,255014218 & 0,351444683 & 0,02582763 & 0,017050819 \\ 0,902656275 & 0,53453057 & 0,315439679 & 0,287467602 & 0,80499545 \\ 0,849957761 & 0,274582567 & 0,528253923 & 0,289150058 & 0,898158752 \\ 0,976594332 & 0,273715432 & 0,817841542 & 0,830663753 & 0,283818239 \\ 0,038306006 & 0,474409974 & 0,137127963 & 0,001066344 & 0,779680672 \\ 0,78979716 & 0,525972097 & 0,331287169 & 0,832602879 & 0,451279841 \\ 0,024422791 & 0,86545398 & 0,029769846 & 0,420171592 & 0,0412621 \\ 0,631497095 & 0,742206691 & 0,813510659 & 0,373865026 & 0,794470284\end{array}$




\begin{tabular}{|c|c|c|c|c|c|}
\hline Serum_Tyrosine & Serum_Glucose & Serum_Mannose & Serum_Proline & Serum_Lactate & Serum_Creatin \\
\hline 0,339591627 & 0,452618261 & 0,812083777 & 0,88568171 & 0,618640505 & 0,093717225 \\
\hline 0,367443525 & 0,339545233 & 0,317417486 & 0,940512426 & 0,549091725 & 0,000530319 \\
\hline 0,311308467 & 0,431776594 & 0,687812226 & 0,597995178 & 0,447864924 & $4,72 \mathrm{E}-07$ \\
\hline 0,537860149 & 0,990063412 & 0,433548445 & 0,31210493 & 0,036784321 & 0,008046353 \\
\hline 0,266829805 & 0,914565349 & 0,449153317 & 0,278352313 & 0,416552307 & 0,000171165 \\
\hline 0,748188709 & 0,889673149 & 0,838084414 & 0,029456631 & 0,016254747 & $5,76 \mathrm{E}-08$ \\
\hline 0,215253085 & 0,412243001 & 0,749982487 & 0,175361003 & 0,770453834 & 0,037684158 \\
\hline 0,556316419 & 0,176214703 & 0,988066805 & 0,547083266 & 0,143631526 & $1,02 \mathrm{E}-05$ \\
\hline 0,82173936 & 0,530085088 & 0,312483916 & 0,244050186 & 0,727447028 & 0,025455383 \\
\hline 0,567087433 & 0,818564302 & 0,532252937 & 0,21086128 & 0,701973635 & 0,688964299 \\
\hline 0,585954263 & 0,017006025 & 0,015250075 & 0,081542471 & 0,008131741 & 0,385737023 \\
\hline 0,972006599 & 0,005083659 & 0,066784659 & 0,589713565 & 0,685473838 & 0,131629623 \\
\hline 0,145485359 & 0,64670308 & 0,218748652 & 0,015696555 & 0,71927251 & 0,001290039 \\
\hline 0,644974697 & 0,400490358 & 0,950056536 & 0,332752883 & 0,24012597 & 0,107197653 \\
\hline 0,763479711 & 0,558770937 & 0,012361314 & 0,860136536 & 0,610107676 & 0,00048755 \\
\hline 0,093668221 & 0,196510816 & 0,079061931 & 0,820760696 & 0,581170849 & 0,255646462 \\
\hline 1,07E-09 & 0,612303026 & 0,828355515 & 0,117710481 & 0,551859802 & 0,128833918 \\
\hline 0,117367157 & 0,941484368 & 0,975497602 & 0,013394188 & 0,029096824 & 0,308092804 \\
\hline 0 & 0,578677909 & 0,07151579 & 0,551254078 & 0,494545231 & 0,462396603 \\
\hline 0,578677909 & 0 & $1,85 \mathrm{E}-10$ & 0,021373444 & 0,296934733 & 0,869469985 \\
\hline 0,07151579 & $1,85 \mathrm{E}-10$ & 0 & 0,290727401 & 0,24725549 & 0,285396841 \\
\hline 0,551254078 & 0,021373444 & 0,290727401 & 0 & 0,250525887 & 0,919056637 \\
\hline 0,494545231 & 0,296934733 & 0,24725549 & 0,250525887 & 0 & 0,715317883 \\
\hline 0,462396603 & 0,869469985 & 0,285396841 & 0,919056637 & 0,715317883 & 0 \\
\hline 0,980660081 & 0,376325628 & 0,12352725 & 0,427670594 & 0,121813079 & 0,039520764 \\
\hline 0,064978698 & 0,935129007 & 0,467354474 & 0,196021258 & 0,262170501 & 0,949555094 \\
\hline 0,28492716 & 0,323552375 & 0,136122017 & 0,961305482 & 0,205104665 & 4,58E-05 \\
\hline 0,009049887 & 0,387987568 & 0,726498705 & 0,30176419 & 0,978562935 & 0,196425533 \\
\hline 0,055256733 & 0,804590269 & 0,932584635 & 0,056587838 & 0,142853605 & 0,007424382 \\
\hline 0,130437551 & 0,004267191 & 0,066371805 & 0,003332378 & 0,000613449 & 0,631462045 \\
\hline 0,891934147 & 0,038006419 & 0,039970811 & 0,591745382 & $7,62 \mathrm{E}-09$ & 0,696779548 \\
\hline 0,149463806 & 0,124941836 & 0,432131793 & $2,72 \mathrm{E}-14$ & 0,578321578 & 0,213272371 \\
\hline 0,791781401 & 0,121915632 & 0,146664615 & 0,049861331 & 0,781119412 & 0,856116099 \\
\hline 0,07295559 & 0,216879884 & 0,475451579 & 0,829378685 & 0,072311057 & 0,008028998 \\
\hline 0,501056297 & 0,398227527 & 0,341422177 & 0,21677919 & $1,10 E-57$ & 0,732648947 \\
\hline 0,249136714 & 0,1034725 & 0,219352174 & $1,94 \mathrm{E}-18$ & 0,412056921 & 0,290384691 \\
\hline $3,03 E-05$ & 0,416273473 & 0,838288426 & 0,16265564 & 0,019526454 & 0,895038368 \\
\hline 0,00198325 & 0,579370439 & 0,455311628 & 0,668239499 & 0,910700078 & 0,638003539 \\
\hline $5,30 \mathrm{E}-05$ & 0,258955089 & 0,382142533 & 0,19971271 & 0,114072792 & 0,227233562 \\
\hline 0,56140087 & 0,294866111 & 0,222421457 & 0,479581923 & 0,244973196 & 0,819348623 \\
\hline 0,474288974 & 0,027034089 & 0,038823008 & 0,963375492 & 0,23695739 & 0,926643236 \\
\hline 0,841859258 & 0,240302618 & 0,022735597 & 0,744324078 & 0,711053532 & 0,018300841 \\
\hline 0,279723592 & 0,686887558 & 0,118983414 & 0,720131658 & 0,765715303 & 0,000213945 \\
\hline 0,728162759 & 0,94946623 & 0,99474657 & 0,768316325 & 0,264272301 & 0,743273376 \\
\hline 0,974257914 & 0,054380049 & 0,083435033 & 0,140457702 & 0,933497269 & 0,817733477 \\
\hline 0,12294523 & 0,051236601 & 0,103052821 & 0,000158057 & 0,787693165 & 0,109249877 \\
\hline 0,721473374 & 0,018042473 & 0,005731907 & 0,290725041 & 0,966937753 & 0,006042391 \\
\hline 0,914436427 & 0,513545834 & 0,059456932 & 0,471376919 & 0,164521469 & 0,739336885 \\
\hline 0,898086429 & 0,26784511 & 0,089013812 & 0,720527796 & 0,777293658 & 0,961093893 \\
\hline
\end{tabular}




$\begin{array}{cccccc}0,874244519 & 0,807762785 & 0,619490108 & 0,00046148 & 0,447863589 & 0,639937858 \\ 0,549258571 & 0,311848421 & 0,391988162 & 0,001281586 & 0,984514497 & 0,604117668 \\ 0,353076695 & 0,606296351 & 0,506943277 & 0,026231398 & 0,973666277 & 0,221294165 \\ 0,822947547 & 0,914278432 & 0,596833442 & 0,457247027 & 0,000425491 & 0,947153175 \\ 0,5185902 & 0,074956815 & 0,010486822 & 0,61236525 & 0,08991658 & 0,099672282 \\ 0,805168896 & 0,10450757 & 0,45612478 & 0,002699807 & 0,903789822 & 0,282555369 \\ 0,001142506 & 0,967140541 & 0,777562095 & 0,574294076 & 0,707295573 & 0,225667169 \\ 0,965121584 & 0,349691159 & 0,347808265 & 0,000652726 & 0,819486535 & 0,462733013 \\ 0,607391482 & 0,307120313 & 0,246931114 & 0,011732765 & 0,712196663 & 0,580887942 \\ 0,211543437 & 0,082661253 & 0,025566823 & 9,09 \mathrm{E}-06 & 0,055218943 & 0,567110863 \\ 0,00680011 & 0,497168226 & 0,249120985 & 0,458360358 & 0,192136581 & 0,036479092 \\ 0,089073048 & 0,005715128 & 0,006851 & 0,881519357 & 0,663554311 & 0,060519022 \\ 0,67819644 & 0,865381659 & 0,359824561 & 0,456311778 & 0,511474503 & 0,458441136 \\ 0,951066573 & 0,204117567 & 0,587953817 & 1,92 \mathrm{E}-05 & 0,713410524 & 0,926146819\end{array}$




\begin{tabular}{|c|c|c|c|c|c|}
\hline Serum_Creatine & Serum_Glycerol & Serum_Glycine & Serum_Citrate & Serum_Glutamine & Serum_Glutan \\
\hline 0,353846912 & 0,075775927 & 0,038199058 & 0,916234547 & 0,003056405 & 0,686243587 \\
\hline 0,799370029 & 0,002255549 & 0,004076541 & 0,042192807 & $4,96 \mathrm{E}-05$ & 0,309565463 \\
\hline 0,444217198 & 0,004155571 & $2,77 \mathrm{E}-06$ & 0,153996626 & 0,000346763 & 0,866216226 \\
\hline 0,588426137 & 0,002499224 & $1,48 \mathrm{E}-07$ & 0,112998916 & $4,68 \mathrm{E}-06$ & 0,769919456 \\
\hline 0,446749715 & 0,384403786 & 0,0721069 & 0,004914769 & 0,003236008 & 0,483425584 \\
\hline 0,047177776 & 0,195654097 & 0,000615424 & 0,543021654 & 0,000387529 & 0,070132347 \\
\hline 0,809793643 & 0,527531666 & 0,403314692 & 0,059592788 & 0,973491207 & 0,276084148 \\
\hline 0,069492836 & 0,186631637 & 0,039411014 & 0,416551475 & 0,002764736 & 0,47104733 \\
\hline 0,017487401 & 0,09087613 & 0,641789085 & 0,722395736 & 0,002530403 & 0,930760238 \\
\hline 0,001610282 & 0,040633972 & 0,58103911 & 0,106747813 & 0,418989985 & 0,054440361 \\
\hline 0,02686604 & 0,009771421 & 0,852331984 & 0,159779494 & 0,11549038 & 0,000494221 \\
\hline 0,553212326 & 0,91680474 & 0,137001276 & 0,197859819 & 0,147990069 & 0,236027367 \\
\hline 0,598524745 & 0,039928124 & 0,259302997 & 0,008364475 & 0,011060347 & 0,972242076 \\
\hline 0,014594798 & 0,009995566 & 0,572865945 & 0,957297606 & 0,355338376 & 0,242842526 \\
\hline $1,15 E-05$ & 0,25928607 & 0,846559827 & 0,053449558 & 0,057536998 & 0,261616595 \\
\hline 0,621770908 & 0,101444596 & 0,144554056 & 0,009182904 & 0,078473096 & 0,828948674 \\
\hline 0,573339965 & 0,391185333 & 0,019371941 & 0,00048827 & 0,000906612 & 0,027761348 \\
\hline 0,088501185 & 0,136811003 & 0,000358889 & 0,000570279 & $7,52 \mathrm{E}-11$ & 0,023805081 \\
\hline 0,980660081 & 0,064978698 & 0,28492716 & 0,009049887 & 0,055256733 & 0,130437551 \\
\hline 0,376325628 & 0,935129007 & 0,323552375 & 0,387987568 & 0,804590269 & 0,004267191 \\
\hline 0,12352725 & 0,467354474 & 0,136122017 & 0,726498705 & 0,932584635 & 0,066371805 \\
\hline 0,427670594 & 0,196021258 & 0,961305482 & 0,30176419 & 0,056587838 & 0,003332378 \\
\hline 0,121813079 & 0,262170501 & 0,205104665 & 0,978562935 & 0,142853605 & 0,000613449 \\
\hline 0,039520764 & 0,949555094 & $4,58 \mathrm{E}-05$ & 0,196425533 & 0,007424382 & 0,631462045 \\
\hline 0 & 0,001877811 & 0,815387376 & 0,387619058 & 0,604029593 & 0,031773772 \\
\hline 0,001877811 & 0 & 0,24611953 & 0,081893732 & 0,004636135 & 0,487861743 \\
\hline 0,815387376 & 0,24611953 & 0 & 0,012576101 & 6,07E-07 & 0,98365678 \\
\hline 0,387619058 & 0,081893732 & 0,012576101 & 0 & $2,12 \mathrm{E}-06$ & 0,139062202 \\
\hline 0,604029593 & 0,004636135 & $6,07 E-07$ & $2,12 \mathrm{E}-06$ & 0 & 0,198066161 \\
\hline 0,031773772 & 0,487861743 & 0,98365678 & 0,139062202 & 0,198066161 & 0 \\
\hline 0,039540481 & 0,110909866 & 0,818408565 & 0,45703275 & 0,253671151 & 0,005461219 \\
\hline 0,859408186 & 0,009364875 & 0,139419088 & 0,861404162 & 0,699024302 & 0,393274745 \\
\hline 0,165104226 & 0,304918796 & 0,038054357 & 0,90936631 & 0,522556765 & 0,542414736 \\
\hline 0,060568072 & 0,112196242 & 0,000269014 & 0,361771752 & 0,0126503 & 0,003160266 \\
\hline 0,15430006 & 0,324277861 & 0,148720378 & 0,931031725 & 0,097928934 & 0,000830751 \\
\hline 0,837010765 & 0,029590187 & 0,155001659 & 0,274820604 & 0,206787936 & 0,255768206 \\
\hline 0,174214129 & 0,151687647 & 0,027437832 & 0,31012344 & 0,02171241 & 0,000188505 \\
\hline 0,071557484 & 0,65687413 & 0,845752972 & 0,968771857 & 0,79564728 & 0,042693355 \\
\hline 0,237973497 & 0,219964497 & 0,079219824 & 0,446319233 & 0,059150793 & 0,000236682 \\
\hline 0,973889267 & 0,714132866 & 0,411926912 & 0,246305062 & 0,766127585 & 0,067381644 \\
\hline 0,459458993 & 0,32070589 & 0,576909625 & 0,373326728 & 0,452830954 & 0,368013602 \\
\hline 0,633650142 & 0,405378066 & 0,115134076 & 0,297529583 & 0,646787116 & 0,467455338 \\
\hline 0,039352518 & 0,628874954 & 0,159604965 & 0,864973644 & 0,38398386 & 0,779710977 \\
\hline 0,917566679 & 0,747216496 & 0,231523926 & 0,831539687 & 0,899343591 & 0,305813613 \\
\hline 0,198963148 & 0,75074452 & 0,862971579 & 0,632486302 & 0,68872331 & 0,0613967 \\
\hline 0,737365943 & 0,933280664 & 0,011680327 & 0,210739712 & 0,422018653 & 0,155868944 \\
\hline 0,781260645 & 0,633856593 & 0,0369262 & 0,047646381 & 0,236156091 & 0,865304611 \\
\hline 0,701657034 & 0,724502239 & 0,204039957 & 0,913483476 & 0,362127665 & 0,536640953 \\
\hline 0,449240475 & 0,529136241 & 0,340267017 & 0,422326174 & 0,140839501 & 0,897519942 \\
\hline
\end{tabular}




$\begin{array}{cccccc}0,683958044 & 0,263122286 & 0,432196241 & 0,855258307 & 0,214016906 & 0,032523202 \\ 0,6816126 & 0,678439864 & 0,852004526 & 0,218734252 & 0,992063509 & 0,949576308 \\ 0,410402682 & 0,56919603 & 0,730211812 & 0,208919634 & 0,86153118 & 0,602588891 \\ 0,361121814 & 0,469020832 & 0,054337071 & 0,584870514 & 0,487204504 & 0,027518844 \\ 0,472571087 & 0,917296576 & 0,171561036 & 0,733351136 & 0,497501111 & 0,233369172 \\ 0,774603456 & 0,745260232 & 0,098331206 & 0,157214695 & 0,332966841 & 0,787006461 \\ 0,550105656 & 0,577827405 & 0,719636117 & 0,131596127 & 0,024070191 & 0,019582976 \\ 0,637980216 & 0,705301397 & 0,86584181 & 0,225039038 & 0,685600136 & 0,938603119 \\ 0,333137494 & 0,783738085 & 0,74535409 & 0,285404585 & 0,620053882 & 0,966991498 \\ 0,221662983 & 0,29105889 & 0,723804609 & 0,332183365 & 0,179489535 & 0,324132722 \\ 0,656904857 & 0,499582725 & 0,169410234 & 0,302113184 & 0,757983585 & 0,619645254 \\ 0,183627969 & 0,331248463 & 0,115903669 & 0,040468328 & 0,87122218 & 0,405094354 \\ 0,303530338 & 0,527764006 & 0,796035272 & 0,608181585 & 0,023030168 & 0,357045547 \\ 0,612139939 & 0,245674143 & 0,784137211 & 0,107837042 & 0,533711105 & 0,839126654\end{array}$




\begin{tabular}{|c|c|c|c|c|}
\hline Serum_Pyruvate & Serum_Acetoacetate & Serum_Acetate & Serum_Alanine & Serum_Threonine.Lactate \\
\hline 0,826007504 & 0,470273434 & 0,097138963 & 0,382596989 & 0,587337551 \\
\hline 0,055916514 & 0,858590831 & 0,480519751 & 0,425365937 & 0,6481484 \\
\hline 0,823306588 & 0,832739803 & 0,587112739 & 0,0087336 & 0,383671844 \\
\hline 0,820338657 & 0,339591029 & 0,125009009 & 0,041668403 & 0,016183354 \\
\hline 0,859488055 & 0,684607732 & 0,530707271 & 0,056745717 & 0,388283778 \\
\hline 0,829460312 & 0,321745038 & 0,516542677 & 0,278307348 & 0,011057623 \\
\hline 0,267338419 & 0,673675625 & 0,750848738 & 0,026592649 & 0,792534123 \\
\hline 0,779759528 & 0,707792011 & 0,627599578 & 0,732505213 & 0,127935585 \\
\hline 0,081241306 & 0,242083513 & 0,02012605 & 0,794948829 & 0,7573684 \\
\hline 0,941731913 & 0,45808865 & 0,790311255 & 0,193047777 & 0,63367472 \\
\hline 0,000207472 & 0,651434983 & 0,674484471 & 0,004511371 & 0,011434683 \\
\hline 0,538911481 & 0,887773035 & 0,097047168 & 0,891843279 & 0,786896933 \\
\hline 0,90549866 & 0,20863056 & 0,081590975 & 0,323440846 & 0,677311817 \\
\hline 0,176365336 & 0,509283829 & 0,275119827 & 0,259167845 & 0,226178741 \\
\hline 0,446909555 & 0,0404585 & 0,13120018 & 0,126344209 & 0,719909636 \\
\hline 0,696821753 & 0,797248909 & 0,001520974 & 0,304259955 & 0,634385553 \\
\hline 0,956298305 & 0,664147512 & 0,406420391 & 0,001435913 & 0,54049008 \\
\hline 0,373223496 & 0,484305452 & 0,851552078 & 0,022914362 & 0,016453689 \\
\hline 0,891934147 & 0,149463806 & 0,791781401 & 0,07295559 & 0,501056297 \\
\hline 0,038006419 & 0,124941836 & 0,121915632 & 0,216879884 & 0,398227527 \\
\hline 0,039970811 & 0,432131793 & 0,146664615 & 0,475451579 & 0,341422177 \\
\hline 0,591745382 & $2,72 E-14$ & 0,049861331 & 0,829378685 & 0,21677919 \\
\hline $7,62 \mathrm{E}-09$ & 0,578321578 & 0,781119412 & 0,072311057 & $1,10 E-57$ \\
\hline 0,696779548 & 0,213272371 & 0,856116099 & 0,008028998 & 0,732648947 \\
\hline 0,039540481 & 0,859408186 & 0,165104226 & 0,060568072 & 0,15430006 \\
\hline 0,110909866 & 0,009364875 & 0,304918796 & 0,112196242 & 0,324277861 \\
\hline 0,818408565 & 0,139419088 & 0,038054357 & 0,000269014 & 0,148720378 \\
\hline 0,45703275 & 0,861404162 & 0,90936631 & 0,361771752 & 0,931031725 \\
\hline 0,253671151 & 0,699024302 & 0,522556765 & 0,0126503 & 0,097928934 \\
\hline 0,005461219 & 0,393274745 & 0,542414736 & 0,003160266 & 0,000830751 \\
\hline 0 & 0,580294009 & 0,728466047 & 0,005527118 & $7,86 \mathrm{E}-08$ \\
\hline 0,580294009 & 0 & 0,040059528 & 0,015472375 & 0,53882781 \\
\hline 0,728466047 & 0,040059528 & 0 & 0,079813209 & 0,65692427 \\
\hline 0,005527118 & 0,015472375 & 0,079813209 & 0 & 0,072817186 \\
\hline $7,86 \mathrm{E}-08$ & 0,53882781 & 0,65692427 & 0,072817186 & 0 \\
\hline 0,58945491 & $8,74 \mathrm{E}-22$ & 0,04775239 & 0,214431457 & 0,368174367 \\
\hline 0,112175916 & 0,961056648 & 0,779995527 & 0,00514816 & 0,016220278 \\
\hline 0,75746578 & 0,348849897 & 0,028990071 & 0,04904314 & 0,894764006 \\
\hline 0,189003368 & 0,634957453 & 0,177279388 & 0,000234742 & 0,111380587 \\
\hline 0,610685289 & 0,336186795 & 0,414972997 & 0,880676075 & 0,270339884 \\
\hline 0,066549317 & 0,743542194 & 0,73377025 & 0,268596293 & 0,333323311 \\
\hline 0,685363886 & 0,643558769 & 0,330438261 & 0,998619847 & 0,565386496 \\
\hline 0,679736968 & 0,709904641 & 0,935028195 & 0,674807801 & 0,834167067 \\
\hline 0,585998295 & 0,726303904 & 0,730356387 & 0,732410212 & 0,270847768 \\
\hline 0,95706324 & 0,373586966 & 0,009126308 & 0,753312112 & 0,921610996 \\
\hline 0,815278716 & 0,000506565 & 0,428097627 & 0,820865092 & 0,79620695 \\
\hline 0,470804622 & 0,838667746 & 0,031191632 & 0,214385264 & 0,797757198 \\
\hline 0,723573692 & 0,438778109 & 0,47996864 & 0,509676965 & 0,177368681 \\
\hline 0,952781877 & 0,788647921 & 0,283768229 & 0,647544382 & 0,8600507 \\
\hline
\end{tabular}




$\begin{array}{ccccc}0,824635107 & 0,02626163 & 0,701449865 & 0,150564156 & 0,379141009 \\ 0,499688759 & 0,02971911 & 0,874926413 & 0,301476577 & 0,98393111 \\ 0,704597943 & 0,606066724 & 0,503977319 & 0,180906536 & 0,982382037 \\ 0,043140172 & 0,54952095 & 0,327621488 & 0,250146451 & 0,000253969 \\ 0,172363417 & 0,424448511 & 0,168652786 & 0,129240831 & 0,079232219 \\ 0,885162385 & 0,093531473 & 0,295962666 & 0,123899729 & 0,882409949 \\ 0,46832819 & 0,624564837 & 0,895322237 & 0,421931602 & 0,6811014 \\ 0,488851274 & 0,021243205 & 0,814290709 & 0,174668079 & 0,846840289 \\ 0,852792538 & 0,131000814 & 0,639523094 & 0,515269927 & 0,676262002 \\ 0,267437837 & 0,000453788 & 0,740585546 & 0,550011476 & 0,048591858 \\ 0,727332793 & 0,038318481 & 0,930507372 & 0,259252967 & 0,183703652 \\ 0,182695092 & 0,423640269 & 0,197829816 & 0,010328333 & 0,664864134 \\ 0,248640221 & 0,46302638 & 0,362309933 & 0,536953996 & 0,510954496 \\ 0,462773711 & 1,46 \mathrm{E}-04 & 0,816880582 & 0,562749353 & 0,745859899\end{array}$


Serum_3.hydroxybutyrate

0,542883613
0,798971172
0,801210543
0,330276065
0,41403093
0,465410902
0,913581949
0,944014917
0,112728413
0,369259791
0,729700086
0,848755604
0,025918919
0,957856293
0,608490637
0,260266919
0,718189758
0,113392486
0,249136714
0,1034725

0,219352174 $1,94 \mathrm{E}-18$

0,412056921

0,290384691

0,837010765

0,029590187

0,155001659

0,274820604

0,206787936

0,255768206

0,58945491

$8,74 \mathrm{E}-22$

0,04775239

0,214431457

0,368174367

0

0,995309029

0,655357025

0,988287479

0,403695856

0,751394908

0,911607811

0,267381205

0,492890234

0,361336245

0,000178271

0,831679589

0,510617752

0,912777552 $\begin{array}{cc}\text { Serum_Valine Serum_Isoleucine } \\ 0,37173781 & 0,000342616\end{array}$

0,368266772

0,243249943

0,118675784

0,454597965

0,05998955

0,031345942

0,260169663

0,018712565

0,943329339

0,004842318

0,32643852

0,434291028

0,6571612

0,146246896

0,466342018

1,16E-05

1,47E-05

3,03E-05

0,416273473

0,838288426

0,16265564

0,019526454

0,895038368

0,174214129

0,151687647

0,027437832

0,31012344

0,02171241

0,000188505

0,112175916

0,961056648

0,779995527

0,00514816

0,016220278

0,995309029

$$
0
$$

1,39E-07

1,35E-15

0,693432701

0,277964552

0,854731579

0,287229533

0,809381681

0,68974208

0,992866726

0,67947353

0,045740811

0,97802799
0,000342616

0,330184879

0,925857751

0,371590251

0,708061451

0,690285757

0,003543113

0,172336866

0,054382846

0,892108128

0,019913483

0,023677649

0,604221819

0,49378496

0,981093398

0,964431566

9,39E-05

0,066369081

0,00198325

0,579370439

0,455311628

0,668239499

0,910700078

0,638003539

0,071557484

0,65687413

0,845752972

0,968771857

0,79564728

0,042693355

0,75746578

0,348849897

0,028990071

0,04904314

0,894764006

0,655357025

1,39E-07

0

6,70E-18

0,909410108

0,703933912

0,755639579

0,249080235

0,952874873

0,522056242

0,713981324

0,978189249

0,405677364

0,704704845
Serum_Leucine

0,083114164

0,890600144

0,102495724

0,255279929

0,933684283

0,062975097

0,001889823

0,53131784

0,213740761

0,897567149

0,005553855

0,089871353

0,889905345

0,77154555

0,975604104

0,798500985

1,26E-08

0,000190972

5,30E-05

0,258955089

0,382142533

0,19971271

0,114072792

0,227233562

0,237973497

0,219964497

0,079219824

0,446319233

0,059150793

0,000236682

0,189003368

0,634957453

0,177279388

0,000234742

0,111380587

0,988287479

1,35E-15

$6,70 \mathrm{E}-18$

0

0,66458168

0,67972021

0,773173057

0,147873891

0,877136533

0,334006669

0,987214803

0,35621115

0,139839744

0,891322504
Sputum_propionato

0,217615562

0,837905835

0,949889125

0,797969941

0,915804833

0,750170618

0,010773968

0,375787704

0,005017084

0,918245888

0,249475953

0,252670952

0,878415345

0,998768442

0,967016563

0,433399622

0,872916385

0,079149346

0,56140087

0,294866111

0,222421457

0,479581923

0,244973196

0,819348623

0,973889267

0,714132866

0,411926912

0,246305062

0,766127585

0,067381644

0,610685289

0,336186795

0,414972997

0,880676075

0,270339884

0,403695856

0,693432701

0,909410108

0,66458168

0

0,185201099

0,467375177

0,823071992

6,34E-16

0,13682913

0,773268972

0,441496715

0,17773126

0,333164801 


$\begin{array}{ccccc}0,004762933 & 0,381431688 & 0,884459107 & 0,347518579 & 0,21823667 \\ 0,004065532 & 0,093473004 & 0,048208288 & 0,080939371 & 0,648142271 \\ 0,228661469 & 0,033739143 & 0,018042857 & 0,044036272 & 0,71810582 \\ 0,738509985 & 0,033706592 & 0,571415415 & 0,258398511 & 0,846655479 \\ 0,805973241 & 0,355803487 & 0,20054322 & 0,166964677 & 0,536856958 \\ 0,007678189 & 0,263204202 & 0,531392724 & 0,283171069 & 0,600147715 \\ 0,485205172 & 0,087249065 & 0,499623539 & 0,21027867 & 0,388282381 \\ 0,002138806 & 0,243836082 & 0,186961502 & 0,19165724 & 0,874257613 \\ 0,032429135 & 0,251168814 & 0,187831527 & 0,290832311 & 0,888153209 \\ 5,14 \mathrm{E}-07 & 0,67655525 & 0,923735777 & 0,645787727 & 0,429395352 \\ 0,056986767 & 0,021969355 & 0,004642056 & 0,011738507 & 0,087040355 \\ 0,762850492 & 0,224329874 & 0,918636034 & 0,701773217 & 0,631426663 \\ 0,428931941 & 0,24129365 & 0,007283138 & 0,028872078 & 0,007990989 \\ 3,60 \mathrm{E}-06 & 0,420257663 & 0,745227765 & 0,587860153 & 0,578739076\end{array}$


Sputum_lactate

0,846408517

0,091101254

0,536894228

0,430572299

0,555978917

0,637149396

0,463031909

0,418868327

0,170468443

0,924772579

0,019532451

0,025236419

0,972921015

0,392944397

0,702037875

0,750866891

0,676738125

0,899518042

0,474288974

0,027034089

0,038823008

0,963375492

0,23695739

0,926643236

0,459458993

0,32070589

0,576909625

0,373326728

0,452830954

0,368013602

0,066549317

0,743542194

0,73377025

0,268596293

0,333323311

0,751394908

0,277964552

0,703933912

0,67972021

0,185201099

0

0,113734918

0,278952119

0,103837133

0,890903693

0,072308978

0,219233088

0,007699775

0,423668908
Sputum_acetoin

0,287902821

0,558022676

0,02373043

0,922003494

0,030595625

0,15530533

0,808946565

0,259725427

0,752163948

0,410289767

0,172281285

0,847029911

0,003660995

0,298631409

0,016004939

0,752913357

0,64999811

0,411681573

0,841859258

0,240302618

0,022735597

0,744324078

0,711053532

0,018300841

0,633650142

0,405378066

0,115134076

0,297529583

0,646787116

0,467455338

0,685363886

0,643558769

0,330438261

0,998619847

0,565386496

0,911607811

0,854731579

0,755639579

0,773173057

0,467375177

0,113734918

0

0,010016301

0,043658338

0,405793132

0,685593543

$1,06 \mathrm{E}-13$

0,113938377

0,143460336
Sputum_alanine

0,47703496

0,283104644

0,000497132

0,247906337

0,446178067

0,00020027

0,517106521

0,010440889

0,172549014

0,302164328

0,287337519

0,574404048

0,689430055

0,253537095

0,138701632

0,917925764

0,043928613

0,585800648

0,279723592

0,686887558

0,118983414

0,720131658

0,765715303

0,000213945

0,039352518

0,628874954

0,159604965

0,864973644

0,38398386

0,779710977

0,679736968

0,709904641

0,935028195

0,674807801

0,834167067

0,267381205

0,287229533

0,249080235

0,147873891

0,823071992

0,278952119

0,010016301

$$
0
$$

0,255054587

0,957178984

0,643192669

0,02709552

0,288493145

0,005387636
Sputum_acetate

0,973311229

0,901515744

0,520469865

0,583819908

0,655981481

0,624937309

0,174908788

0,848749623

0,036119824

0,45218379

0,067565

0,349962278

0,887329141

0,620593395

0,63603831

0,277795038

0,647799319

0,221626292

0,728162759

0,94946623

0,99474657

0,768316325

0,264272301

0,743273376

0,917566679

0,747216496

0,231523926

0,831539687

0,899343591

0,305813613

0,585998295

0,726303904

0,730356387

0,732410212

0,270847768

0,492890234

0,809381681

0,952874873

0,877136533

6,34E-16

0,103837133

0,043658338

0,255054587

0

0,589474705

0,978707297

0,035108046

0,330722334

0,097754661
Sputum_acetone

0,436966035

0,919055303

0,858569339

0,372994

0,081127906

0,755820158

0,244002855

0,257992563

0,876507818

0,773525093

0,772963378

0,408075926

0,04400457

0,281640263

0,651727877

0,252898656

0,352276183

0,162454315

0,974257914

0,054380049

0,083435033

0,140457702

0,933497269

0,817733477

0,198963148

0,75074452

0,862971579

0,632486302

0,68872331

0,0613967

0,95706324

0,373586966

0,009126308

0,753312112

0,921610996

0,361336245

0,68974208

0,522056242

0,334006669

0,13682913

0,890903693

0,405793132

0,957178984

0,589474705

0

0,050880638

0,239512726

0,502511827

0,045339424 


$\begin{array}{lllll}0,224166819 & 0,700902115 & 0,095875809 & 0,134021452 & 0,771525364 \\ 0,072391406 & 0,073884465 & 0,069072176 & 0,500824481 & 0,331253414 \\ 0,125449628 & 0,11005944 & 0,026152888 & 0,819538209 & 0,274480501 \\ 0,617552711 & 0,70337384 & 0,710205145 & 0,51230133 & 0,356912675 \\ 0,415715566 & 0,278376087 & 0,554340394 & 0,435256849 & 0,419347036 \\ 0,382445551 & 0,067209067 & 0,414851122 & 0,52854465 & 0,386478245 \\ 0,419291856 & 0,148268597 & 0,386909017 & 0,160831509 & 0,728441356 \\ 0,060982143 & 0,087308353 & 0,109586515 & 0,656188991 & 0,370108761 \\ 0,014928827 & 0,125745189 & 0,011935097 & 0,840899025 & 0,401166543 \\ 0,680164687 & 0,297372699 & 0,925847478 & 0,512954676 & 0,513008255 \\ 0,563385544 & 0,499585229 & 0,126790217 & 0,264851444 & 0,317276471 \\ 0,964749465 & 0,783484079 & 0,964183443 & 0,897236634 & 0,692932191 \\ 0,723570228 & 0,045732291 & 0,547682128 & 0,011273237 & 0,851589162 \\ 0,300259705 & 0,078462555 & 0,394667181 & 0,310135425 & 0,395614881\end{array}$


Sputum_succinate

0,434811297

0,083442757

0,529133618

0,133848698

0,335675926

0,399743875

0,793689

0,011921293

0,438180798

0,247537366

0,013657375

0,00120318

0,12855208

0,374771095

0,523896307

0,25578183

0,472140836

0,936214029

0,12294523

0,051236601

0,103052821

0,000158057

0,787693165

0,109249877

0,737365943

0,933280664

0,011680327

0,210739712

0,422018653

0,155868944

0,815278716

0,000506565

0,428097627

0,820865092

0,79620695

0,000178271

0,992866726

0,713981324

0,987214803

0,773268972

0,072308978

0,685593543

0,643192669

0,978707297

0,050880638

0

0,905400706

0,367141237

0,977474647
Sputum_unk

0,448367122

0,5226045

0,010036186

0,577906683

0,009935104

0,209387766

0,129211263

0,956791726

0,302401993

0,999922446

0,132480562

0,645226083

0,001143426

0,076060671

0,010095759

0,715187978

0,03325506

0,796029475

0,721473374

0,018042473

0,005731907

0,290725041

0,966937753

0,006042391

0,781260645

0,633856593

0,0369262

0,047646381

0,236156091

0,865304611

0,470804622

0,838667746

0,031191632

0,214385264

0,797757198

0,831679589

0,67947353

0,978189249

0,35621115

0,441496715

0,219233088

$1,06 \mathrm{E}-13$

0,02709552

0,035108046

0,239512726

0,905400706

0

0,586779364

0,015595336
Sputum_taurine

0,224300775

0,858748264

0,985405807

0,314207222

0,289542443

0,351248436

0,291450212

0,159161566

0,409921066

0,603669454

0,286220258

0,860705468

0,230236684

0,278998678

0,512767091

0,298461459

0,553748091

0,052636981

0,914436427

0,513545834

0,059456932

0,471376919

0,164521469

0,739336885

0,701657034

0,724502239

0,204039957

0,913483476

0,362127665

0,536640953

0,723573692

0,438778109

0,47996864

0,509676965

0,177368681

0,510617752

0,045740811

0,405677364

0,139839744

0,17773126

0,007699775

0,113938377

0,288493145

0,330722334

0,502511827

0,367141237

0,586779364

0

1,19E-05
Sputum_glycine

0,153075009

0,541675422

0,563836121

0,82192991

0,267087395

0,841923423

0,408177677

0,538536681

0,110501481

0,830018441

0,944292295

0,726034577

0,342186095

0,103277177

0,699817351

0,359150113

0,179890135

0,141675058

0,898086429

0,26784511

0,089013812

0,720527796

0,777293658

0,961093893

0,449240475

0,529136241

0,340267017

0,422326174

0,140839501

0,897519942

0,952781877

0,788647921

0,283768229

0,647544382

0,8600507

0,912777552

0,97802799

0,704704845

0,891322504

0,333164801

0,423668908

0,143460336

0,005387636

0,097754661

0,045339424

0,977474647

0,015595336

1,19E-05

0
Sputum_formate

0,804288324

0,647283152

0,803108718

0,327376292

0,733897698

0,331497791

0,955560946

0,847537879

0,284888516

0,200432423

0,929877915

0,410984862

0,161466568

0,964160052

0,908143942

0,984266533

0,670772731

0,255970489

0,874244519

0,807762785

0,619490108

0,00046148

0,447863589

0,639937858

0,683958044

0,263122286

0,432196241

0,855258307

0,214016906

0,032523202

0,824635107

0,02626163

0,701449865

0,150564156

0,379141009

0,004762933

0,381431688

0,884459107

0,347518579

0,21823667

0,224166819

0,700902115

0,095875809

0,134021452

0,771525364

0,902616365

0,761229248

0,199916329

0,011137295 


$\begin{array}{ccccc}0,902616365 & 0,761229248 & 0,199916329 & 0,011137295 & 0 \\ 2,11 \mathrm{E}-05 & 0,076702401 & 0,800108089 & 0,577736059 & 0,103316662 \\ 0,002244205 & 0,157130682 & 0,709778787 & 0,844391254 & 0,151645935 \\ 0,553568663 & 0,93926344 & 0,611081889 & 0,091774101 & 0,007433914 \\ 0,893007587 & 0,44268078 & 0,892126263 & 0,281569797 & 0,003535979 \\ 0,006592542 & 0,02955565 & 0,227124597 & 0,871972866 & 0,174332681 \\ 0,608634477 & 0,351703312 & 0,512149408 & 0,194424183 & 0,277756421 \\ 6,26 \mathrm{E}-06 & 0,060290752 & 0,764838532 & 0,589358113 & 0,065741875 \\ 3,10 \mathrm{E}-05 & 0,157266141 & 0,746040279 & 0,268842643 & 0,319848621 \\ 0,002274069 & 0,38087981 & 0,842004273 & 0,651973096 & 8,59 \mathrm{E}-05 \\ 0,522882941 & 0,238520902 & 0,229040869 & 0,513583038 & 0,322825584 \\ 0,48701998 & 0,533891206 & 0,491433584 & 0,555854756 & 0,134046028 \\ 0,996558994 & 0,118913128 & 0,901937601 & 0,108385919 & 0,711372602 \\ 9,61 \mathrm{E}-06 & 0,074814443 & 0,575081399 & 0,472917931 & 0,085507131\end{array}$


EBC_Leucine.n.butyrate

\begin{tabular}{ccc}
0,292230134 & 0,087799629 & 0,252164811 \\
0,343675971 & 0,283780099 & 0,119702021 \\
0,443038525 & 0,380542474 & 0,715182717 \\
0,271659474 & 0,09769245 & 0,814124502 \\
0,258791626 & 0,211502323 & 0,557726631 \\
0,885645324 & 0,645113804 & 0,600817066 \\
0,272094621 & 0,301804039 & 0,752671235 \\
0,43686133 & 0,484665753 & 0,748247237 \\
0,29087103 & 0,178285955 & 0,016155538 \\
0,841698546 & 0,458131611 & 0,998007102 \\
0,060330471 & 0,035387848 & 0,108344544 \\
0,038876476 & 0,060374223 & 0,865281789 \\
0,052623852 & 0,131426114 & 0,907380597 \\
0,967758337 & 0,324215252 & 0,696029724 \\
0,553874948 & 0,163715243 & 0,647072102 \\
0,301153206 & 0,137666628 & 0,286433184 \\
0,137533552 & 0,090824905 & 0,763794353 \\
0,943758699 & 0,779884448 & 0,215976377 \\
0,549258571 & 0,353076695 & 0,822947547 \\
0,311848421 & 0,606296351 & 0,914278432 \\
0,391988162 & 0,506943277 & 0,596833442 \\
0,001281586 & 0,026231398 & 0,457247027 \\
0,984514497 & 0,973666277 & 0,000425491 \\
0,604117668 & 0,221294165 & 0,947153175 \\
0,6816126 & 0,410402682 & 0,361121814 \\
0,678439864 & 0,56919603 & 0,469020832 \\
0,852004526 & 0,730211812 & 0,054337071 \\
0,218734252 & 0,208919634 & 0,584870514 \\
0,992063509 & 0,86153118 & 0,487204504 \\
0,949576308 & 0,602588891 & 0,027518844 \\
0,499688759 & 0,704597943 & 0,043140172 \\
0,02971911 & 0,606066724 & 0,54952095 \\
0,874926413 & 0,503977319 & 0,327621488 \\
0,301476577 & 0,180906536 & 0,250146451 \\
0,98393111 & 0,982382037 & 0,000253969 \\
0,004065532 & 0,228661469 & 0,738509985 \\
0,093473004 & 0,033739143 & 0,033706592 \\
0,048208288 & 0,018042857 & 0,571415415 \\
0,080939371 & 0,044036272 & 0,258398511 \\
0,648142271 & 0,71810582 & 0,846655479 \\
0,072391406 & 0,125449628 & 0,617552711 \\
0,073884465 & 0,11005944 & 0,70337384 \\
0,069072176 & 0,026152888 & 0,710205145 \\
0,500824481 & 0,819538209 & 0,51230133 \\
0,331253414 & 0,274480501 & 0,356912675 \\
0,8001080505 & 0,002244205 & 0,553568663 \\
0,577736059 & 0,157130682 & 0,93926344 \\
& 0,709778787 & 0,611081889 \\
0,844391254 & 0,091774101 \\
\hline
\end{tabular}

EBC_3.hydroxyisovalerate EBC_Lactate 0,943707625

0,761557991

0,258330669

0,876944524

0,100336628

0,033306689

0,585533418

0,315396568

0,222568288

0,002601069

0,596034861

0,816752726

0,926219714

0,089657977

0,261918434

0,655495102

0,569265371

0,134470896

0,973447173

0,047585774

0,066756079

0,620242244

0,244610718

0,034510425

0,162796218

0,805168896

0,10450757

0,45612478

0,002699807

0,903789822

0,282555369

0,774603456

0,745260232

0,098331206

0,157214695

0,332966841

0,787006461

0,885162385

0,093531473

0,295962666

0,123899729

0,882409949

0,007678189

0,263204202

0,531392724

0,283171069

0,600147715

0,382445551

0,067209067

0,414851122

0,52854465

0,386478245

0,006592542

0,02955565

0,227124597

0,871972866 


$\begin{array}{ccccc}0,103316662 & 0,151645935 & 0,007433914 & 0,003535979 & 0,174332681 \\ 0 & 7,18 \mathrm{E}-21 & 0,178727797 & 0,001159395 & 2,29 \mathrm{E}-06 \\ 7,18 \mathrm{E}-21 & 0 & 0,008255752 & 6,33 \mathrm{E}-05 & 5,51 \mathrm{E}-05 \\ 0,178727797 & 0,008255752 & 0 & 1,54 \mathrm{E}-05 & 0,32312061 \\ 0,001159395 & 6,33 \mathrm{E}-05 & 1,54 \mathrm{E}-05 & 0 & 0,001397957 \\ 2,29 \mathrm{E}-06 & 5,51 \mathrm{E}-05 & 0,32312061 & 0,001397957 & 0 \\ 0,752073261 & 0,699495799 & 0,145776507 & 0,089822825 & 0,278449277 \\ 9,58 \mathrm{E}-38 & 5,24 \mathrm{E}-18 & 0,152292284 & 0,00155666 & 4,62 \mathrm{E}-06 \\ 1,19 \mathrm{E}-25 & 2,14 \mathrm{E}-20 & 0,505635466 & 0,00211851 & 0,000261486 \\ 2,00 \mathrm{E}-08 & 2,50 \mathrm{E}-06 & 0,005873078 & 1,54 \mathrm{E}-09 & 3,29 \mathrm{E}-06 \\ 0,036397714 & 0,000120751 & 0,832385291 & 0,751301833 & 0,052239233 \\ 0,893967869 & 0,964017105 & 0,288398984 & 3,30 \mathrm{E}-07 & 0,021864508 \\ 0,009301973 & 0,030505393 & 0,303710932 & 0,00219865 & 0,170364919 \\ 1,21 \mathrm{E}-20 & 9,19 \mathrm{E}-09 & 0,58016178 & 0,054032603 & 7,13 \mathrm{E}-07\end{array}$




\begin{tabular}{|c|c|c|c|c|c|}
\hline 3C_Acetoine & EBC_n.Butyrate & EBC_Acetate & EBC_Acetone & EBC_Trimethylamine & EBC_Methanol \\
\hline 0,894888587 & 0,650865341 & 0,667538907 & 0,464150148 & 0,025912299 & 0,12879765 \\
\hline 0,640609262 & 0,523481804 & 0,666657525 & 0,928417527 & 0,981316853 & 0,910350933 \\
\hline 0,89386138 & 0,306996049 & 0,389627542 & 0,27605977 & 0,308379139 & 0,14932529 \\
\hline 0,795625523 & 0,454382242 & 0,253368855 & 0,471862882 & 0,416349891 & 0,189566733 \\
\hline 0,972914615 & 0,188406631 & 0,340790333 & 0,095753216 & 0,437889637 & 0,247516016 \\
\hline 0,848853886 & 0,78951777 & 0,629786204 & 0,647447397 & 0,622604005 & 0,560577454 \\
\hline 0,391463759 & 0,592422752 & 0,959355083 & 0,45202737 & 0,001244725 & 0,938836292 \\
\hline 0,749072969 & 0,652678382 & 0,948438578 & 0,776285064 & 0,3242326 & 0,715518538 \\
\hline 0,374072855 & 0,545374581 & 0,942831089 & 0,416918463 & 0,049055392 & 0,302673937 \\
\hline 0,194471946 & 0,794850195 & 0,660367055 & 0,272378498 & 0,549944194 & 0,628559952 \\
\hline 0,214467095 & 0,083923507 & 0,242438443 & 0,151995606 & 0,427863623 & 0,338211605 \\
\hline 0,541378478 & 0,056010815 & 0,008028367 & 0,822036304 & 0,999418984 & 0,839841488 \\
\hline 0,544679158 & 0,0334375 & 0,140067924 & 0,015651458 & 0,915747301 & 0,697912096 \\
\hline 0,255539943 & 0,902656275 & 0,849957761 & 0,976594332 & 0,038306006 & 0,78979716 \\
\hline 0,255014218 & 0,53453057 & 0,274582567 & 0,273715432 & 0,474409974 & 0,525972097 \\
\hline 0,351444683 & 0,315439679 & 0,528253923 & 0,817841542 & 0,137127963 & 1287169 \\
\hline 0,02582763 & 0,287467602 & 0,289150058 & 0,830663753 & 0,001066344 & 0,832602879 \\
\hline 0,017050819 & 0,80499545 & 0,898158752 & 0,283818239 & 0,779680672 & 0,451279841 \\
\hline 0,001142506 & 0,965121584 & 0,607391482 & 0,211543437 & 000680 & 0,089073048 \\
\hline 0,967140541 & 0,349691159 & 0,307120313 & 0,08266 & 0,49 & 0,0057 \\
\hline 0,777562095 & 0,347808265 & 0,246931114 & 0,025566823 & 0,249120985 & 0,006851 \\
\hline 0,574294076 & 0,000652726 & 0,011732765 & $9,09 E-06$ & 0,458 & 0,881519357 \\
\hline 0,707295573 & 0,819486535 & 0,712196663 & 0,055218943 & 0,192136581 & 0,663554311 \\
\hline 0,225667169 & 0,462733013 & 0,580887942 & 0,567110863 & 479092 & 0,060519022 \\
\hline 0,550105656 & 0,637980216 & 0,333137494 & 0,221662983 & 0,65690 & 0,183627969 \\
\hline 0,577827405 & 0,705301397 & 0,783738085 & 0,2910 & 0,4 & 463 \\
\hline 0,719636117 & 0,86584181 & 0,74535409 & 0,72380 & 0,16 & 0,115903669 \\
\hline 0,131596127 & 0,225039038 & 0,285404585 & 0,332183365 & 0,302113184 & 0,040468328 \\
\hline 0,024070191 & 0,685600136 & 0,620053882 & 0,179489535 & 0,757983585 & 0,87122218 \\
\hline 0,019582976 & 0,938603119 & 0,966991498 & 0,324132722 & 0,619645254 & 0,405094354 \\
\hline 0,46832819 & 0,488851274 & 0,852792538 & 0,2674 & 0,72 & 0,182695092 \\
\hline 0,624564837 & 0,021243205 & 0,131000814 & 0,000453788 & 0,038318481 & 0,423640269 \\
\hline 0,895322237 & 0,814290709 & 0,639523094 & 0,740585546 & 0,930507372 & 0,197829816 \\
\hline 0,421931602 & 0,174668079 & 0,515269927 & 0,550011476 & 0,259 & 0,010328333 \\
\hline 0,6811014 & 0,846840289 & 0,676262002 & 0,048591858 & 0,183703652 & 0,664864134 \\
\hline 0,485205172 & 0,002138806 & 0,032429135 & $5,14 \mathrm{E}-07$ & 0,056986767 & 0,762850492 \\
\hline 0,087249065 & 0,243836082 & 0,251168814 & 0,67655525 & 0,021969355 & 0,224329874 \\
\hline 0,499623539 & 0,186961502 & 0,187831527 & 0,923735777 & 0,004642056 & 0,918636034 \\
\hline 0,21027867 & 0,19165724 & 0,290832311 & 0,645787727 & 0,011738507 & 0,701773217 \\
\hline 0,388282381 & 0,874257613 & 0,888153209 & 0,429395352 & 0,087040355 & 0,631426663 \\
\hline 0,419291856 & 0,060982143 & 0,014928827 & 0,680164687 & 0,563385544 & 0,964749465 \\
\hline 0,148268597 & 0,087308353 & 0,125745189 & 0,297372699 & 0,499585229 & 0,783484079 \\
\hline 0,386909017 & 0,109586515 & 0,011935097 & 0,925847478 & 0,126790217 & 0,964183443 \\
\hline 0,160831509 & 0,656188991 & 0,840899025 & 0,512954676 & 0,264851444 & 0,897236634 \\
\hline 0,728441356 & 0,370108761 & 0,401166543 & 0,513008255 & 0,317276471 & 0,692932191 \\
\hline 0,608634477 & $6,26 \mathrm{E}-06$ & $3,10 \mathrm{E}-05$ & 0,002274069 & 0,522882941 & 0,48701998 \\
\hline 0,351703312 & 0,060290752 & 0,157266141 & 0,38087981 & 0,238520902 & 0,533891206 \\
\hline 0,512149408 & 0,764838532 & 0,746040279 & 0,842004273 & 0,229040869 & 0,491433584 \\
\hline 0,194424183 & 0,589358113 & 0,268842643 & 0,651973096 & 0,513583038 & 0,555854756 \\
\hline
\end{tabular}




$\begin{array}{cccccc}0,277756421 & 0,065741875 & 0,319848621 & 8,59 \mathrm{E}-05 & 0,322825584 & 0,134046028 \\ 0,752073261 & 9,58 \mathrm{E}-38 & 1,19 \mathrm{E}-25 & 2,00 \mathrm{E}-08 & 0,036397714 & 0,893967869 \\ 0,699495799 & 5,24 \mathrm{E}-18 & 2,14 \mathrm{E}-20 & 2,50 \mathrm{E}-06 & 0,000120751 & 0,964017105 \\ 0,145776507 & 0,152292284 & 0,505635466 & 0,005873078 & 0,832385291 & 0,288398984 \\ 0,089822825 & 0,00155666 & 0,00211851 & 1,54 \mathrm{E}-09 & 0,751301833 & 3,30 \mathrm{E}-07 \\ 0,278449277 & 4,62 \mathrm{E}-06 & 0,000261486 & 3,29 \mathrm{E}-06 & 0,052239233 & 0,021864508 \\ 0 & 0,678045692 & 0,771993632 & 0,096347454 & 0,971414037 & 0,956056272 \\ 0,678045692 & 0 & 6,20 \mathrm{E}-25 & 4,33 \mathrm{E}-09 & 0,114669655 & 0,705655948 \\ 0,771993632 & 6,20 \mathrm{E}-25 & 0 & 8,59 \mathrm{E}-07 & 0,070413511 & 0,785296875 \\ 0,096347454 & 4,33 \mathrm{E}-09 & 8,59 \mathrm{E}-07 & 0 & 0,394260005 & 0,006492755 \\ 0,971414037 & 0,114669655 & 0,070413511 & 0,394260005 & 0 & 0,286465312 \\ 0,956056272 & 0,705655948 & 0,785296875 & 0,006492755 & 0,286465312 & 0 \\ 0,108522602 & 0,035165038 & 0,191339779 & 0,23596492 & 0,06928466 & 0,045771063 \\ 0,658352983 & 4,93 \mathrm{E}-20 & 3,50 \mathrm{E}-13 & 1,96 \mathrm{E}-09 & 0,400363625 & 0,938452901\end{array}$




$\begin{array}{cc}\text { EBC_Phenol } & \text { EBC_Formate } \\ 0,002594529 & 0,682620524 \\ 0,045407925 & 0,799958276 \\ 0,822792933 & 0,418609411 \\ 0,575817271 & 0,851798862 \\ 0,935381617 & 0,129214089 \\ 0,537004739 & 0,827424481 \\ 0,001669685 & 0,479040158 \\ 0,140502225 & 0,704103306 \\ 0,000550503 & 0,801702063 \\ 0,379054451 & 0,921846973 \\ 0,003384687 & 0,207209667 \\ 0,138284322 & 0,404710223 \\ 0,371925648 & 0,01400291 \\ 0,024422791 & 0,631497095 \\ 0,86545398 & 0,742206691 \\ 0,029769846 & 0,813510659 \\ 0,420171592 & 0,373865026 \\ 0,0412621 & 0,794470284 \\ 0,67819644 & 0,951066573 \\ 0,865381659 & 0,204117567 \\ 0,359824561 & 0,587953817 \\ 0,456311778 & 1,92 \mathrm{E}-05 \\ 0,511474503 & 0,713410524 \\ 0,458441136 & 0,926146819 \\ 0,303530338 & 0,612139939 \\ 0,527764006 & 0,245674143 \\ 0,796035272 & 0,784137211 \\ 0,608181585 & 0,107837042 \\ 0,023030168 & 0,533711105 \\ 0,357045547 & 0,839126654 \\ 0,248640221 & 0,462773711 \\ 0,46302638 & 1,46 \mathrm{E}-04 \\ 0,362309933 & 0,816880582 \\ 0,536953996 & 0,562749353 \\ 0,510954496 & 0,745859899 \\ 0,428931941 & 3,60 \mathrm{E}-06 \\ 0,24129365 & 0,420257663 \\ 0,007283138 & 0,745227765 \\ 0,028872078 & 0,587860153 \\ 0,007990989 & 0,578739076 \\ 0,723570228 & 0,300259705 \\ 0,045732291 & 0,078462555 \\ 0,547682128 & 0,394667181 \\ 0,011273237 & 0,310135425 \\ 0,851589162 & 0,395614881 \\ 0,996558994 & 9,61 \mathrm{E}-06 \\ 0,118913128 & 0,074814443 \\ 0,108385919 & 0,472917931\end{array}$



$0,711372602 \quad 0,085507131$
$0,009301973 \quad 1,21 \mathrm{E}-20$
0,030505393 9,19E-09
$0,303710932 \quad 0,58016178$
$0,00219865 \quad 0,054032603$
0,170364919 7,13E-07
$0,108522602 \quad 0,658352983$
$0,035165038 \quad 4,93 \mathrm{E}-20$
$0,191339779 \quad 3,50 \mathrm{E}-13$
$0,23596492 \quad 1,96 \mathrm{E}-09$
$0,06928466 \quad 0,400363625$
$0,045771063 \quad 0,938452901$
$0 \quad 0,197197214$
$0,197197214 \quad 0$ 